\title{
A Detailed Overview and Consistent Classification of Climate-Economy Models
}

\author{
Alexandros Nikas, Haris Doukas, and Andreas Papandreou
}

\begin{abstract}
The proliferation and growing variety of climate-economy models and what are known as integrated assessment models (IAMs) can make it difficult for someone interested in following the debate to place any specific model, or the discussion about the merits of one or another, into a broader context. The literature related to climate-economy modelling is already vast: apart from a very large number of models and an even larger number of applications, there already exist many good surveys comparing — inter alia_-modelling frameworks, model assumptions and model results. The objective of this chapter is to provide a simple overview and organising scheme of this modelling world by delving into the characteristics of more than 60 individual IAMs towards describing the main ways in which certain classes or groups of climate-economy models differ from one another. In contrast to other more detailed or narrowly focused "overviews" and literature reviews, this analysis takes less for granted and aims at providing an initial understanding of generic model structures. After briefly discussing some principles of classification that can help organise this often daunting modelling world, the chapter offers descriptions and comparisons of the main classes of models.
\end{abstract}

Keywords Climate policy · Integrated assessment models · Equilibrium · Macroeconometric $\cdot$ Energy systems $\cdot$ Climate-economy modelling $\cdot$ Optimal growth · Uncertainty

\footnotetext{
A. Nikas $(\bowtie) \cdot$ H. Doukas

Decision Support Systems Laboratory, School of Electrical and Computer Engineering,

National Technical University of Athens, Athens, Greece

e-mail: anikas@epu.ntua.gr; h_doukas@epu.ntua.gr
}

\author{
A. Papandreou \\ Department of Economics, University of Athens, Athens, Greece \\ e-mail: aap@econ.uoa.gr
}




\section{Introduction}

Many modelling frameworks have been developed to provide an understanding of the drivers of climate change and to assist policy formation (Flamos 2016). When climate change emerged as a serious issue in the 1970s, there were no theoretical tools that could provide a more integrated understanding of the phenomenon or provide richer insights into policy response. Models of physical dimensions of the climate system (mostly ecosystem models) were extended to consider the processes by which greenhouse gas emissions were generated and could be limited. General circulation models that dealt with atmospheric parts of the climate system were being linked to ocean models. Economists were modifying global energy-economy analysis to project greenhouse gas emissions, considering ways to reduce them and incorporating aggregated physical dimensions of the climate system. Scientists from different disciplines were linking models and analyses to provide a more integrated understanding of different facets of a highly complex interrelated phenomenon (Weyant 2009).

At a broad level, we can see the following interlinked chain of interactions. Human-induced climate change results from an increase in GHG emissions and their levels of concentration in the atmosphere. Climate science tells us how different concentration levels of GHGs may affect the temperature, precipitation, cloud formation, wind and sea level rise. These changes in turn result in various physical, environmental and social impacts like change in crop yields, water supply, species loss and migration. These impacts can then be translated into monetary terms, or processed through a model of the economy, to give a single measure of the economic cost of climate change. As these changes take place over time, models attempt to project parts or the whole dynamic process of increasing emissions, temperature changes, physical impacts and economic damages. The economy is not only affected by climate change, but it is also the perpetrator of climate change as growth in production and consumption gives rise to more GHG emissions. The most important part of the economy that determines the rate of emissions is the energy system or the forms and uses of energy. Each part of this climate-economy interaction is characterised by uncertainty (Papadelis et al. 2013) and some degree of scientific disagreement.

Various ways of climate-economy modelling can to a large extent be understood by the different ways in which they model parts of this highly interconnected process. Figure 1 below provides a depiction of climate-economy dynamics, identifying four key modules of climate-economy modelling. The climate module describes the link between GHG emission, atmospheric concentrations and the resulting variation in temperature and other climatic changes (precipitation, cloud cover, extreme weather events, climate discontinuities, etc.). The impacts module 
ECONOMY

CLIMATE

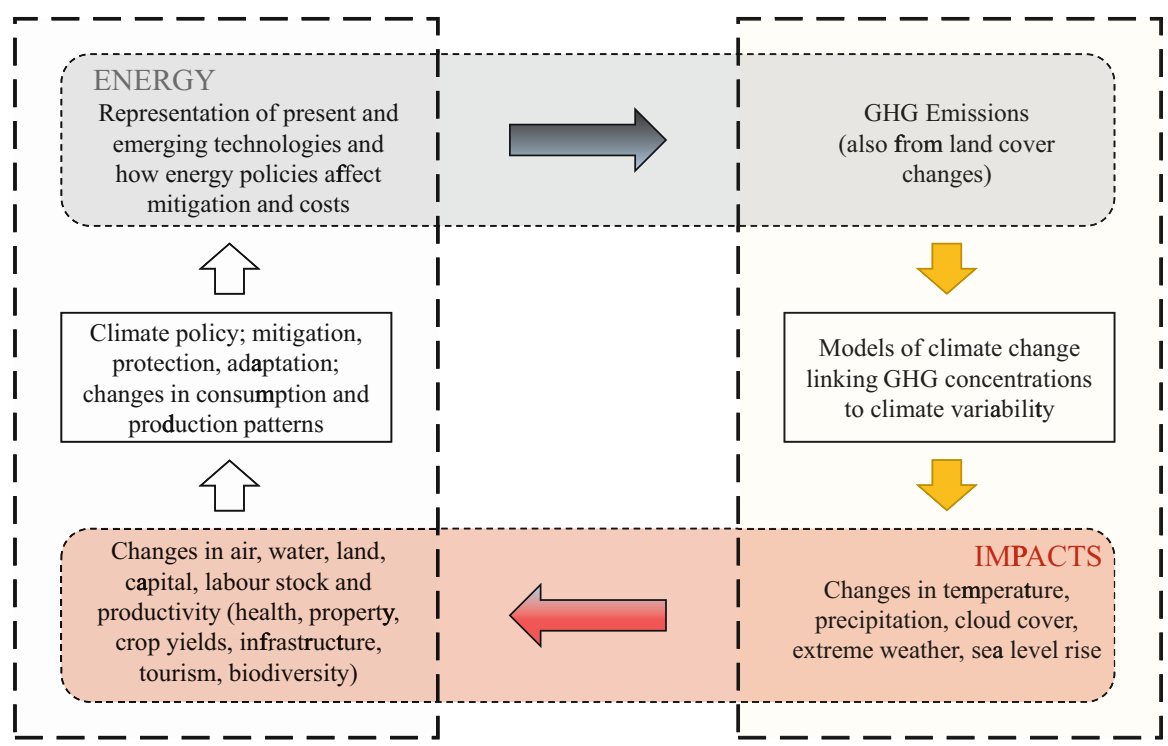

Fig. 1 Climate-economy dynamics with four modules: Economy, climate, impacts, and energy

(or damage function) expresses physical or environmental outcomes as a function of climate variables. For instance, a model might have an agricultural damage function relating variability in temperature, precipitation and cloud cover to crop yields. An economy module may describe the dynamics or growth of an economy, how emissions vary with growth and climate policies and how climate-induced physical and environmental changes might affect parts or all of an economy. The economy model is often augmented with a more detailed energy module that describes the factors determining the uses of different sources of energy and the cost of emission reductions.

The great variety of climate-economy models reflect in part the range of underlying scientific disciplines influencing their development, alternative methodologies and assumptions, as well as the different questions or issues they address. The large and growing number of models and their relative complexity can make it bewildering to distinguish them or understand their unique attributes. There already exist many good reviews of different categories of integrated assessment or climateeconomy models in the literature: Füssel (2009) provides general reviews; a special issue of The Energy Journal provides more detailed and technical comparisons of IAMs (Weyant 1999); Tol and Fankhauser (1998) and Yohe (1999) review the 
modelling and representation of impacts in IAMs; Hitz and Smith (2004) review the way different IAMs deal with the global impacts of climate change as a function of the global mean temperature; and Lecocq and Shalizi (2007) review the literature considering the relationship between growth and climate policy as well as climate change. Other equally thorough reviews can be found in the literature (e.g. Dowlatabadi 1995; Parson and Fisher-Vanden 1997; Kelly and Kolstad 1999; Rana and Morita 2000; Schwanitz 2013; Wei et al. 2015). However, due to the large differences among the models and model categories, these reviews tend to have different perspectives and focus on very specific aspects of the modelling processes, while at the same time using different categorisations.

The objective of this chapter is to look at key characteristics of the available integrated assessment models, while also focusing on their structure and ways of treating uncertainty and technology, in order to help develop a concrete categorisation and form a simple and useful overview of the climate-economy modelling universe. This analysis substantially differs from other often more detailed or narrowly focused "overviews" in that it takes less for granted and aims at providing an initial understanding of generic model structures. This objective is in contrast, for instance, with Ortiz and Markandya (2009), who give short descriptions of many models and their equations, or Stanton et al. (2009) that focus on key assumptions affecting model outcomes or Füssel (2010) that focuses on how adaptation to climate change is incorporated in models. In this respect, this simple and brief overview is meant to complement these other less generic discussions and act as an initial guide to this vast terrain. Section 2 provides an overview of the six classes in which we categorise the existing integrated assessment modelling frameworks. Sections 3-7 present the unique features of each one of the model categories, as well as key characteristics of a large number of representative IAMs. Finally, Sect. 9 concludes the analysis and discusses some key remarks.

It should be noted that there exist in the literature different criteria for considering a modelling framework as an IAM. According to most reviews and from a strict point of view, only models with a close loop between economy and environment effects can be classified as IAMs; thus, most partial equilibrium models cannot be considered alone as IAMs, but can certainly be used as part of an IAM modelling suite. In this research, all models that include separate modules for climate, economy and energy are considered to be IAMs. Exceptions include certain energy system models (Sect. 6) that may not explicitly include a climate module but may rather abstract from climate by including emissions (without climate change or damages), which have also been included in other reviews (e.g. Stanton et al. 2009). 


\section{Classifying Climate-Economy Models}

There exist a large number of various classifications in the literature, which do not fully align with each other or with the one presented in this chapter (e.g. Füssel 2010; Stanton et al. 2009; Ortiz and Markandya 2009; Söderholm 2007). In particular, Füssel (2010) following an older tradition divides them according to the kind of decision analytical frameworks to which they are applied, Stanton et al. (2009) divide them according to model structures and Ortiz and Markandya (2009) classify integrated assessment models by whether all four modules (climate, impacts, economy, energy) are used and how they are combined.

Drawing on these classifications and a detailed literature review of applications, six general modelling structures or approaches are presented. These are distinguished primarily by how the economy is modelled and the way the other three modules (climate, impacts, energy) are integrated. Of course, the nature of these models slightly hinders their consistent classification, given that certain IAMs may inevitably be sorted into more than one class. The six model classes that are presented in the following sections are briefly introduced below:

1. Optimal growth (or welfare optimisation) IAMs represent the economy as a single all-encompassing sector. They are designed to determine the climate policy and investment levels that maximise welfare (future against present consumption) over time, by identifying the emission abatement levels for each time step. They tend to be fairly simple, highly aggregated and transparent models that capture the trajectory of an economy and its interaction with climate in a fully integrated fashion, meaning that all modules are represented and endogenously determined.

2. General equilibrium (or usually referred to as computable general equilibrium-CGE) models have a more detailed representation of the economy with multiple sectors and often include higher resolution of energy technologies and regional detail. Rather than seeking optimal policies, they consider the impacts of specific policies on economic, social and environmental parameters. The richer representation of the economy comes at a cost in that the growth of the economy is harder to model and its structure more complex.

3. Partial equilibrium models provide a detailed analysis of the interaction between environmental impacts and a particular sector of the economy. These are usually used to assess potential climate-induced damages to a specific sector of the economy and are often linked to computable general equilibrium models.

(a) Energy system models can be considered as a subcategory of partial equilibrium models that provide a detailed account of the energy sector, i.e. energy technologies and their associated costs. These are used, inter alia, to determine the least-cost ways of attaining GHG emission reductions or the costs of alternative climate policies. They are often linked with computable general equilibrium or macroeconometric models in order to add the desired level of insight to top-down approaches. 
4. Macroeconometric models, like computable general equilibrium models, can be quite detailed in terms of energy technologies and geographic scope and are also used to evaluate alternative climate policies, but they differ in that they do not assume that consumers and producers behave optimally or that markets clear and reach equilibrium in the short term. Instead, they use historical data and econometrically estimated parameters and relations to dynamically and more realistically simulate the behaviour of the economy.

5. Other integrated assessment models refer to models that may have little in common except that they do not fit neatly into any of the previous well-known groups. A key departure is that they model the economy in a highly "reduced form" or simply use exogenous growth scenarios (no model at all). Although they significantly differ from one another, they all tend to be more policy-oriented than models of the other five classes.

Table 1 provides an overview of characteristics of the different approaches. The first column labels the overall approach, while the remaining columns describe how each approach varies in the way the four different modules are modelled. The table, acting as a reference point and organising principle, also aligns with the descriptions of the six approaches presented in the remainder of the paper so that the different elements in the boxes can be further explained.

The classification scheme presented in Table 1 is not meant to be exhaustive or comprehensive, and models will often not fit neatly into one of these approaches, while many combine elements of different categories. For instance, Füssel (2010) introduces a separate category referred to as "policy guidance models" and represented by ICLIPS (Toth 2005), which integrates the first four approaches into one model. Furthermore, combining models of different categories towards adding the desired level of detail is not uncommon in the climate policy literature; for example, CGE and macroeconometric models are often combined with energy system models. The connection between the different model categories is an important aspect in the modelling literature, given that certain models focus on specific sectors often neglecting the impacts on the other sectors. At the same time, IAMs that cover the energy, economy and climate are criticised for sacrificing the necessary model granularity for the sake of simplicity. From a modelling perspective, this linkage is complex and understudied in the literature (e.g. Karkatsoulis et al. 2017). Table 2 attempts to provide an overview of the six categories of integrated assessment models with some of their most prominent modelling frameworks, along with a short description and set of indicative applications. Sixty-one modelling frameworks have been reviewed and assessed for the purpose of this study. 


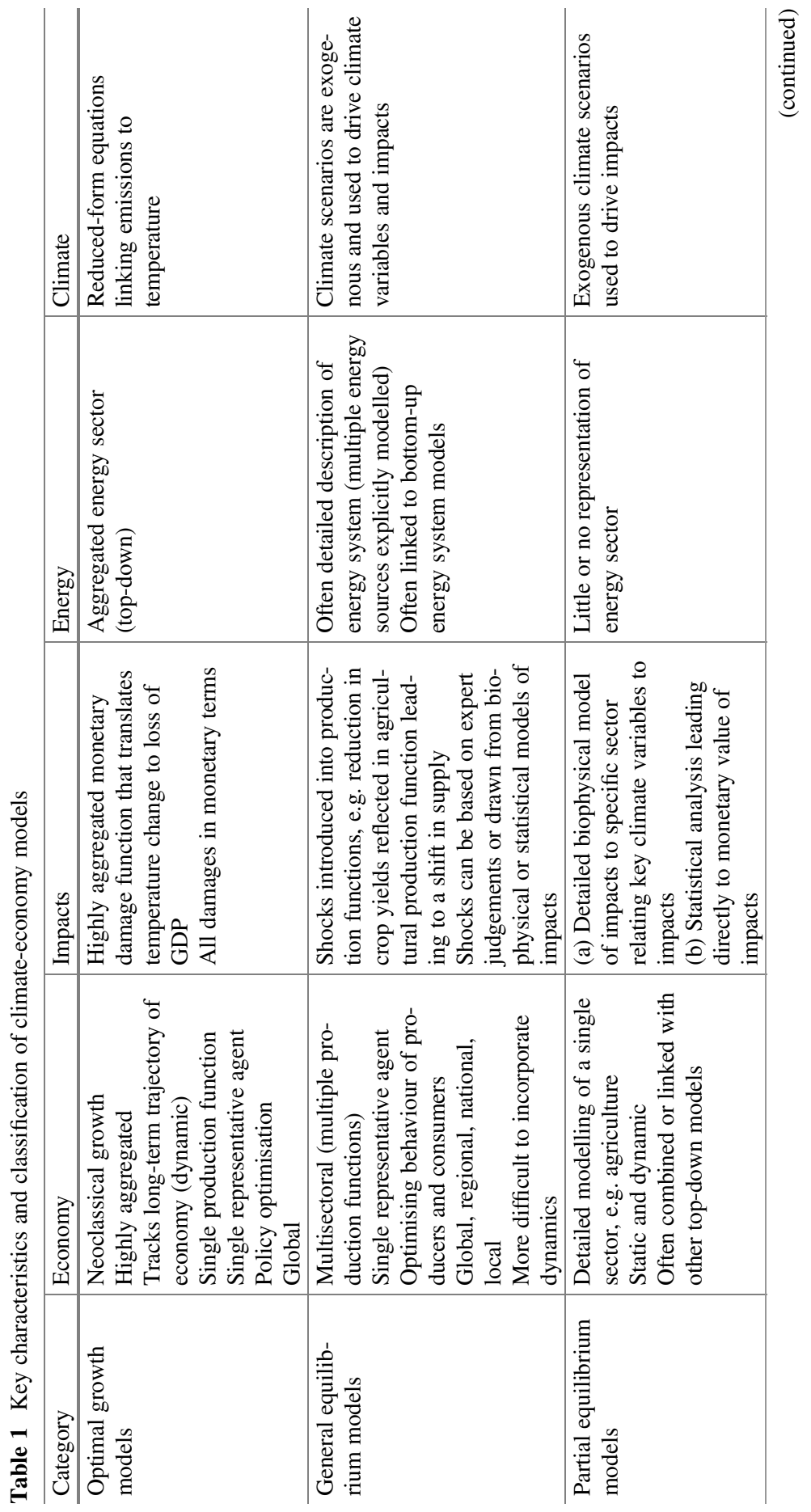




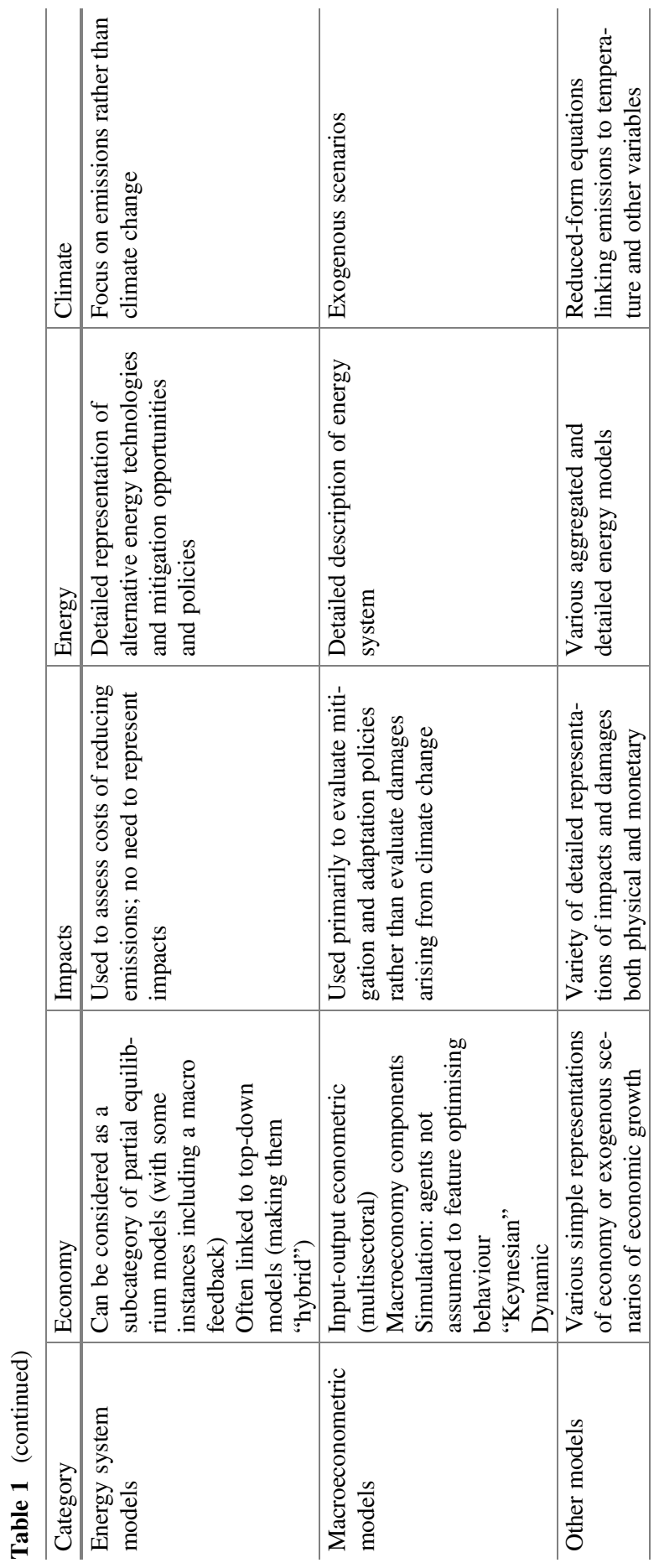




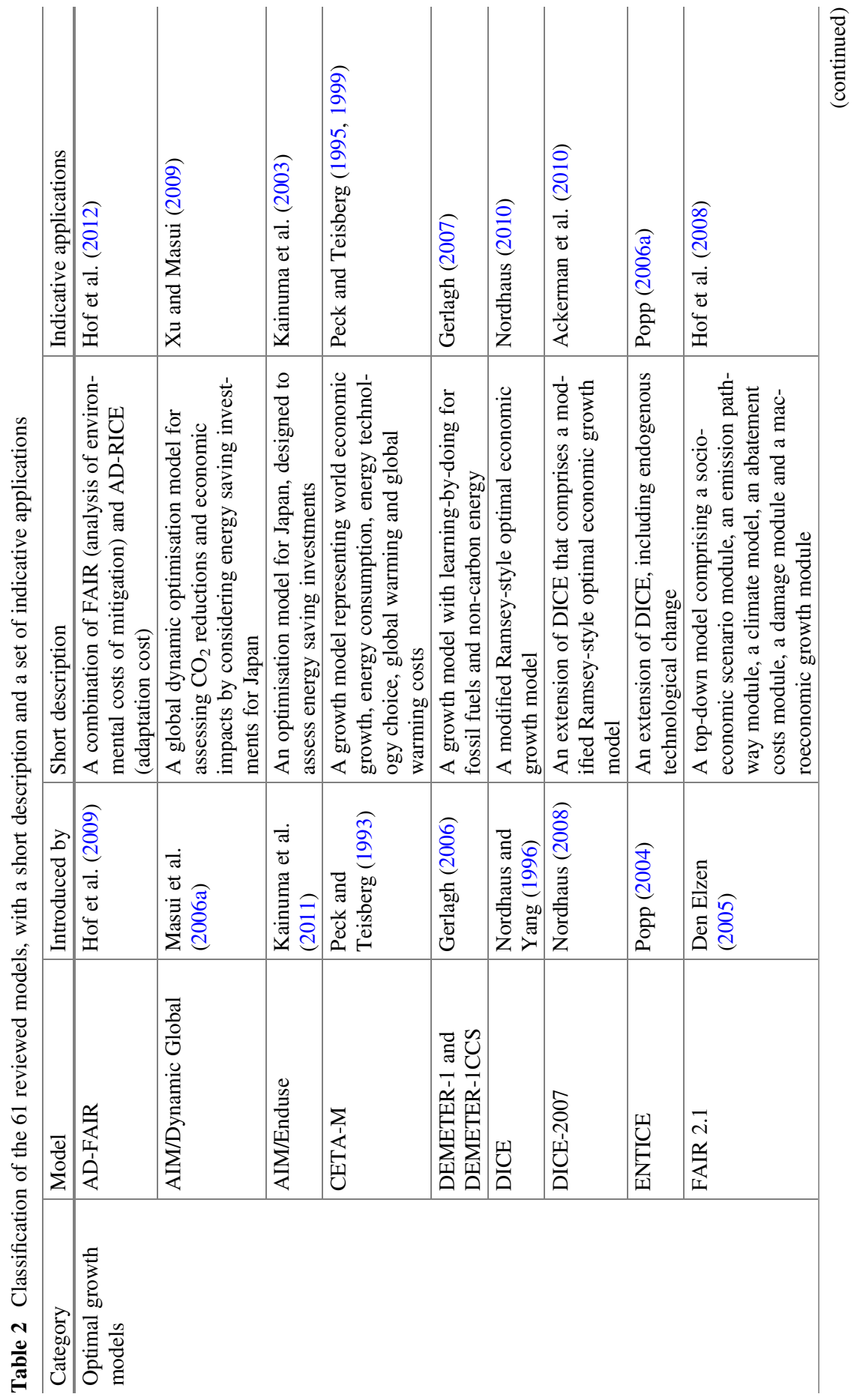




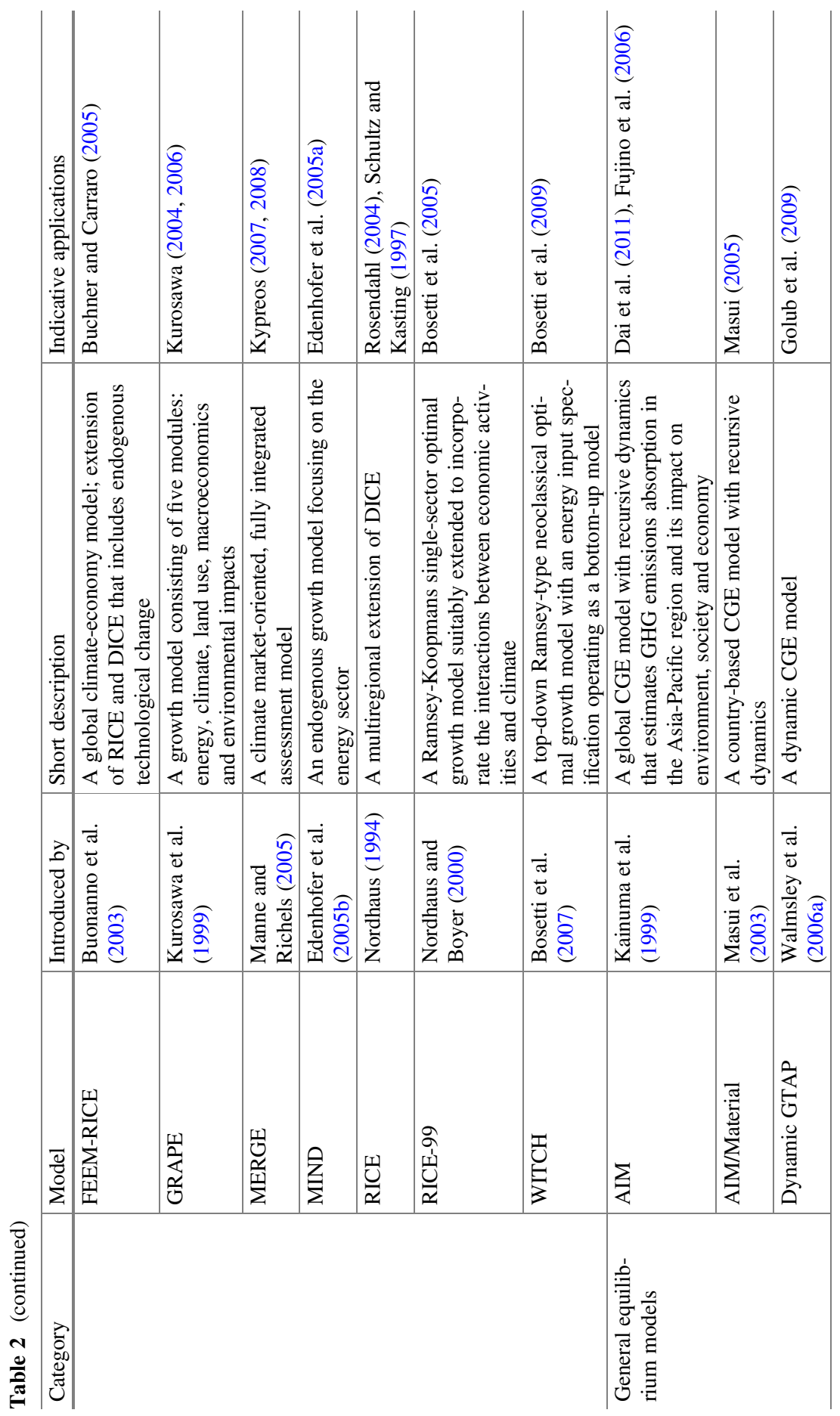




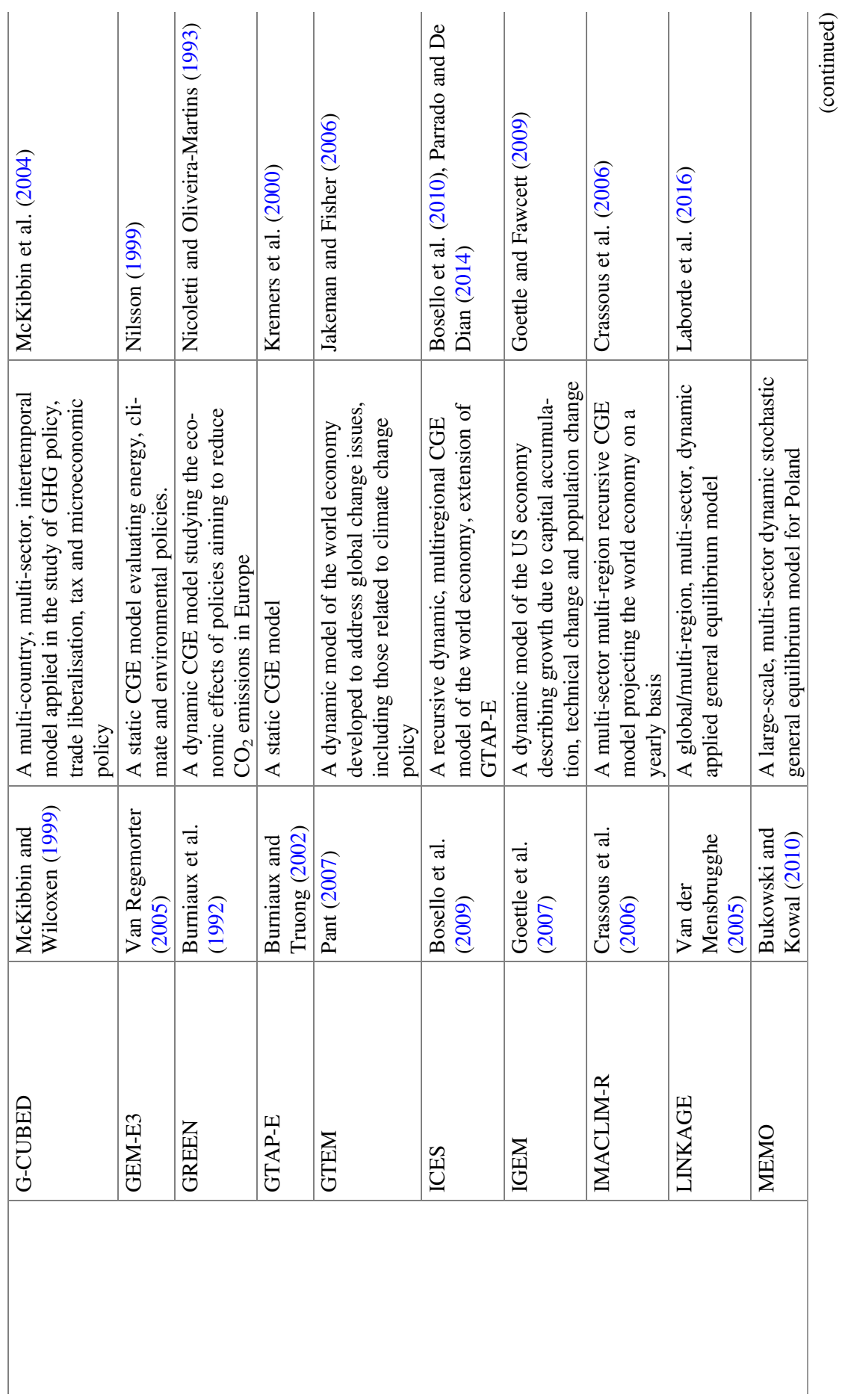




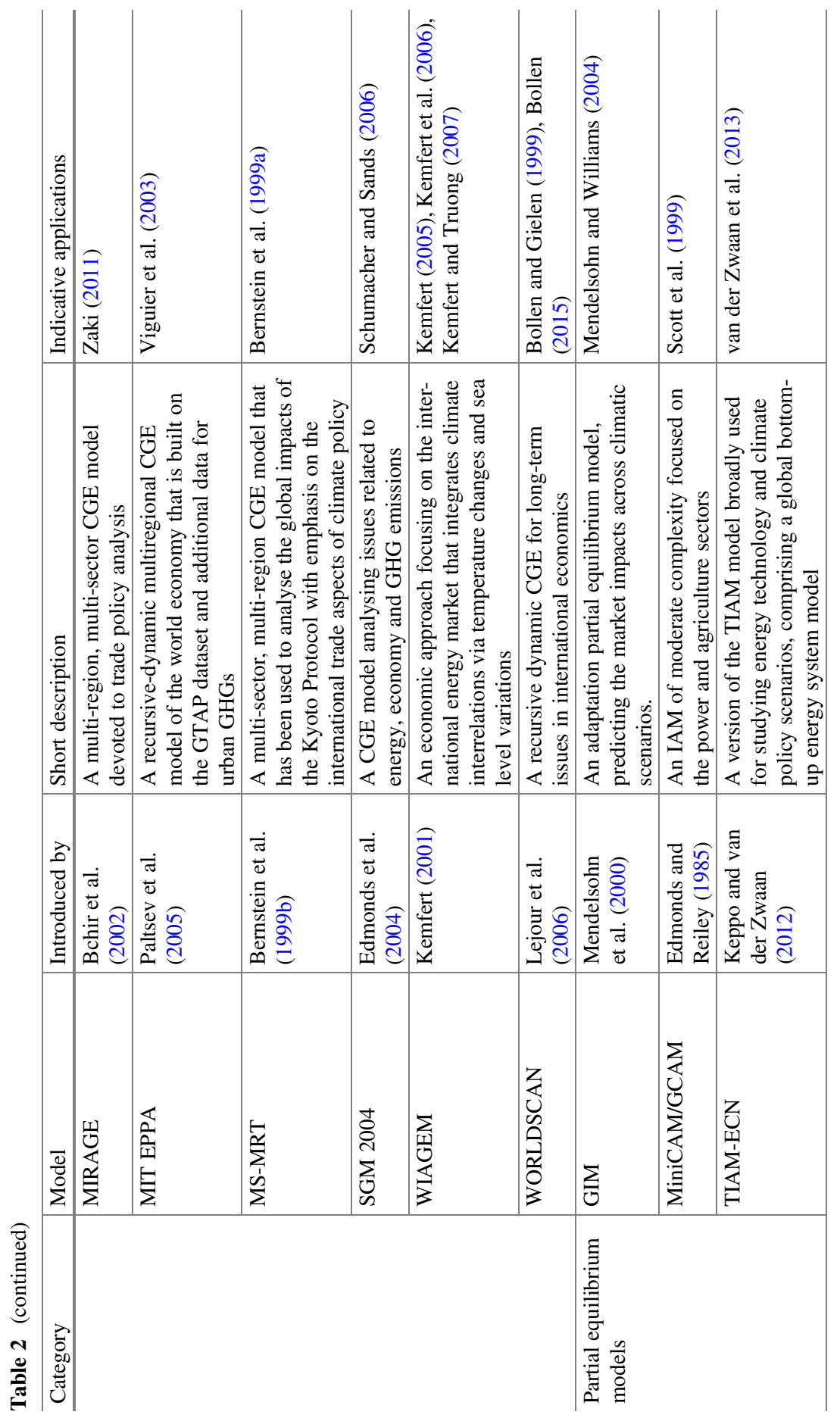




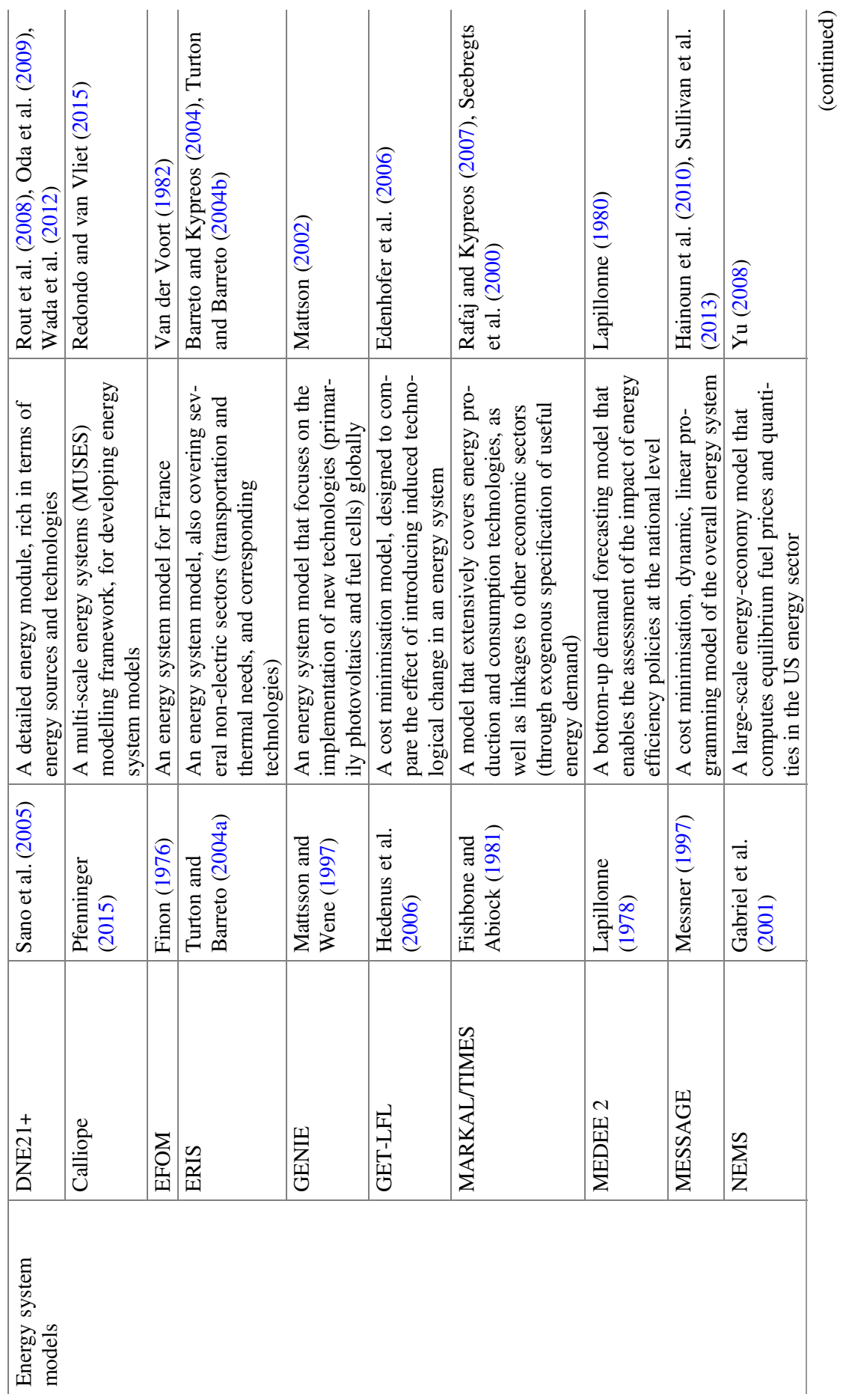




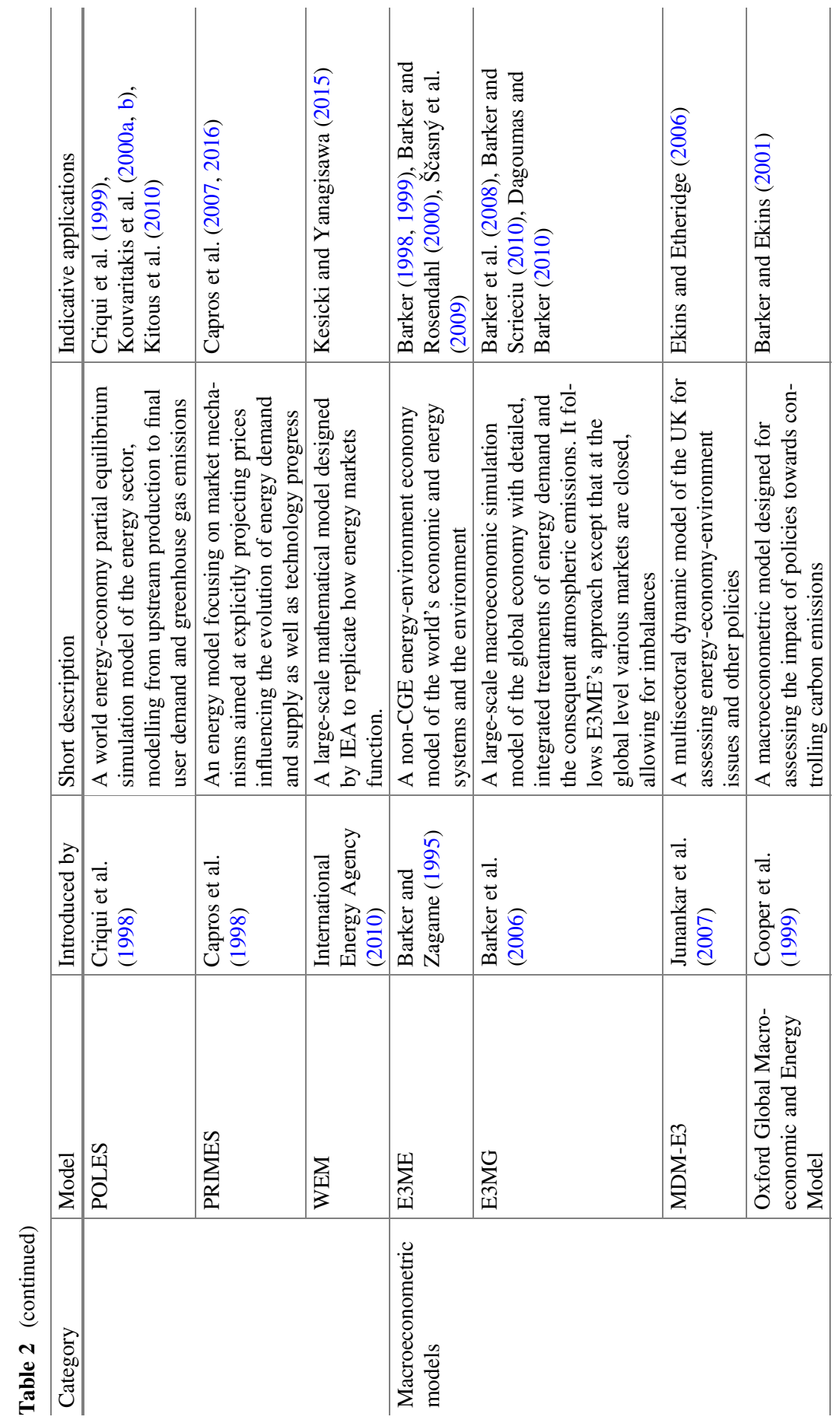




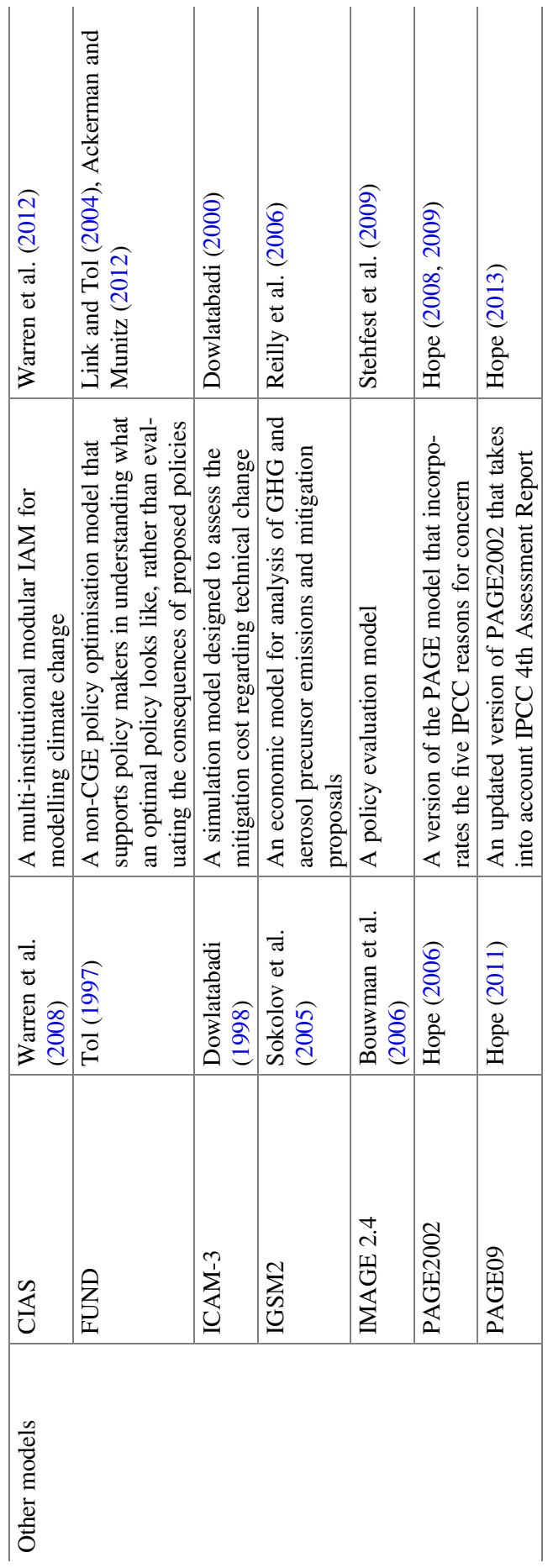




\section{Optimal Growth Models}

Optimal growth or welfare optimisation IAMs tend to be more transparent because they are relatively simple, compared to models of other categories with more complex structures. They have solid microeconomic foundations and focus explicitly on the development of the economy over time. Social welfare is often defined as the utility of a representative agent, and the overall objective is to maximise aggregated welfare over time. In neoclassical economic growth models, economies make investments in capital, education and technologies. These enhance future consumption by sacrificing some present consumption, the objective being to find the right balance between present consumption and investment in future consumption so as to maximise overall welfare. IAMs of this class extend the neoclassical growth models by including the "natural capital" of the climate system as an additional kind of capital (Nordhaus 2014). Increased emissions of GHGs effectively deplete natural capital, while abatement investments augment it. In addition to standard investments, natural capital used today enhances present consumption versus expending resources in order to protect the climate system, or to avoid damage from climate change, for future welfare. In terms of climate policy, these models compare alternative paths of emissions over time (abatement) in order to find the policy that maximises overall social welfare.

Table 3 presents a set of key models falling under this class, along with information regarding the perspective of the model, the number of regions and forecasting period it can cover and the damage function by means of which the damages are translated into monetary terms. The model perspective describes the overall approach of the modelling framework: a top-down approach looks at the system under examination as a whole and uses reduced form behavioural relationships with econometrical validation, while bottom-up approaches are developed from an engineering perspective and start from the sector of interest in detail before expanding the focus onto the whole system. Other settings are more flexible and can be described as being developed from a hybrid perspective, i.e. combine different levels of detail for specific sectors or the system-a particular class of hybrid models are economic engineering models, which combine microeconomic foundations of behaviour with explicit engineering and technology details (see, e.g. Sect. 6).

Most of the modelling frameworks in this category are top-down approaches, with the exception of AIM/Enduse, which can also be considered as a non-integrated assessment model, since no economic module is included. CETA-M, WITCH and MERGE feature a hybrid model perspective, while DEMETER-1(CCS) is a classic top-down model incorporating insights from the bottom-up literature regarding learning-by-doing effects (Ortiz and Markandya 2009).

The DICE (dynamic integrated climate economy) global model (Nordhaus and Yang 1996) is selected in this study as a representative model of this category. In DICE, countries are aggregated into a single level of output, capital stock, technology and emissions (in a regional setting, RICE is a multi-region version of DICE). The social welfare function represents the world's well-defined set of preferences 


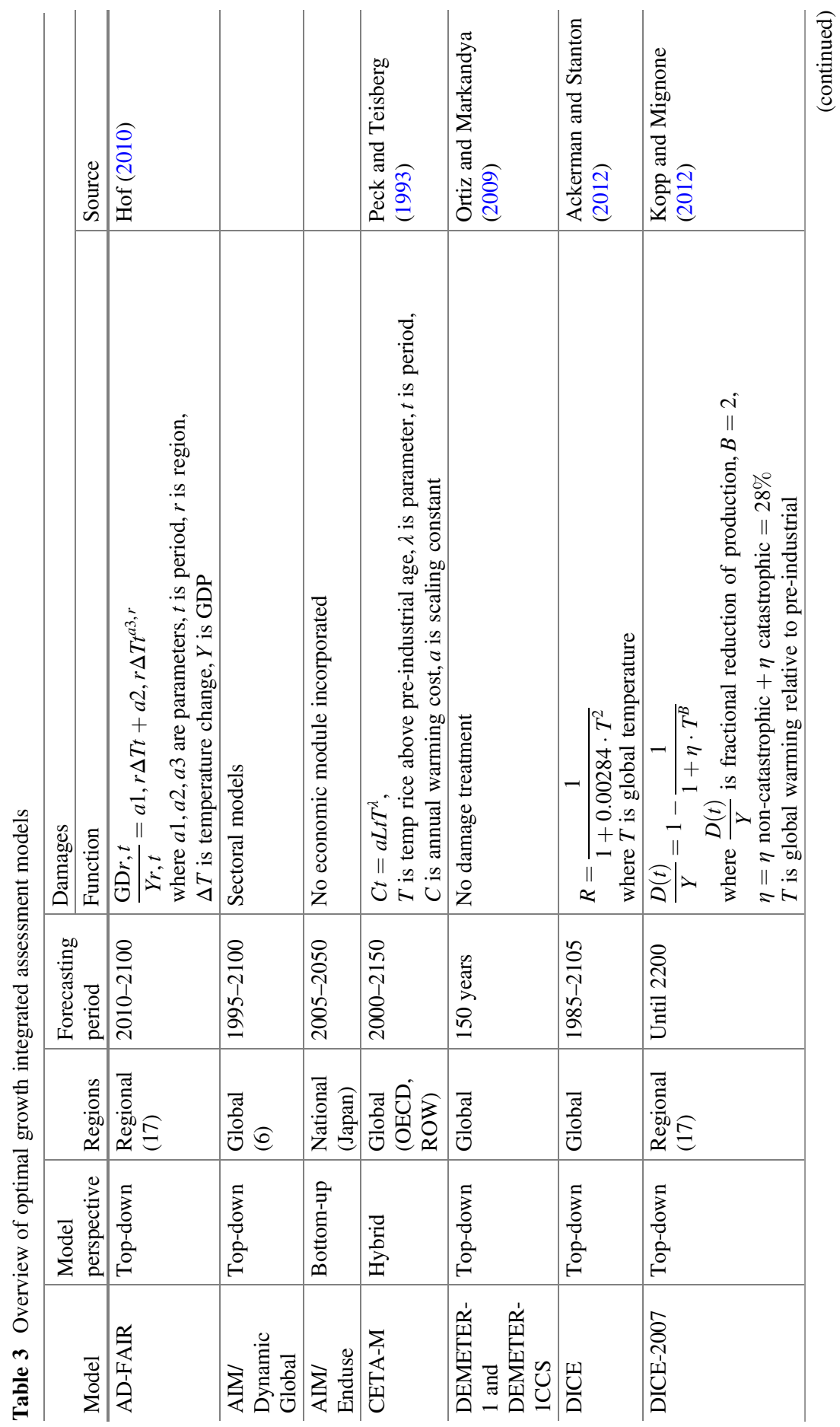




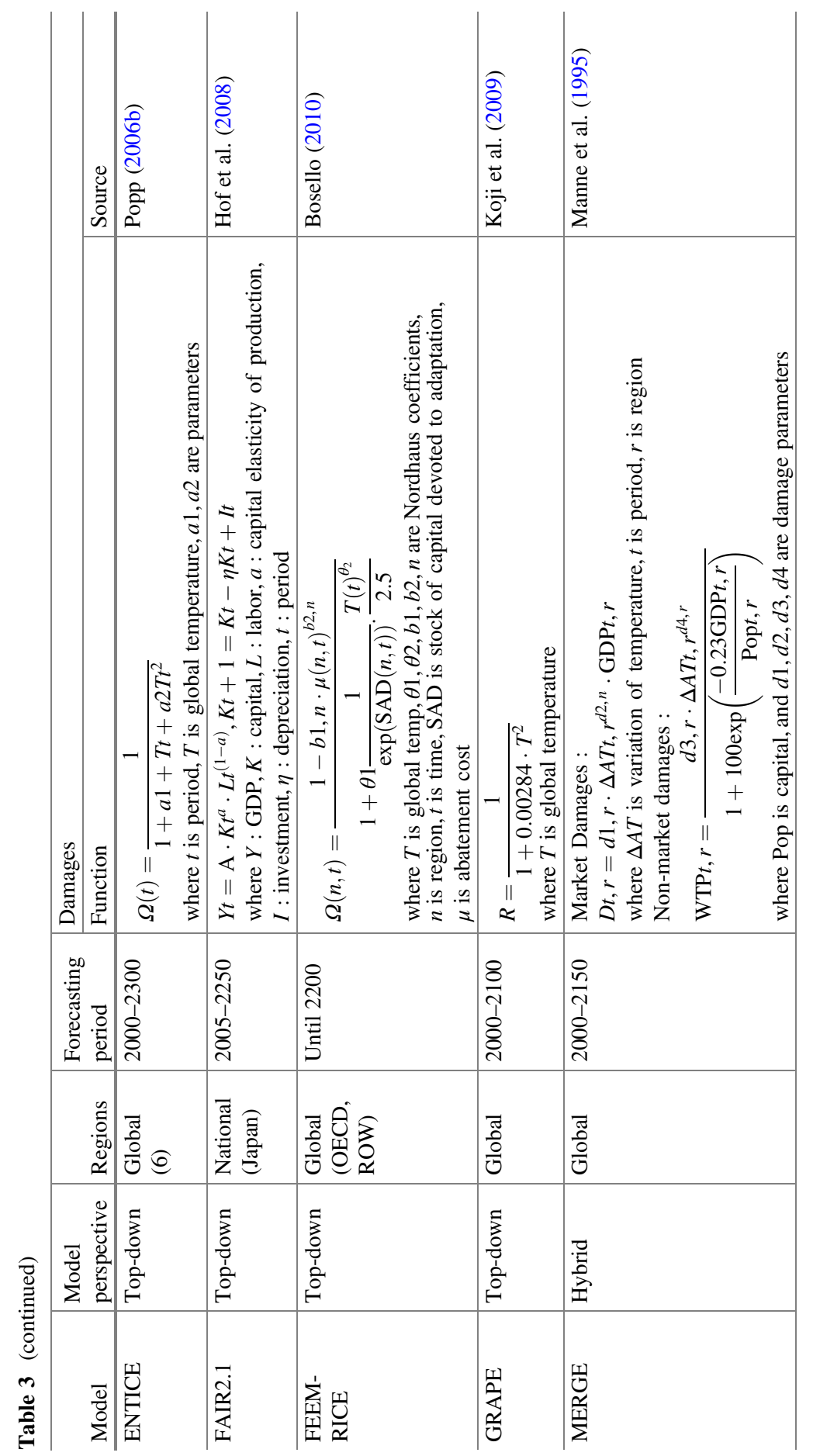




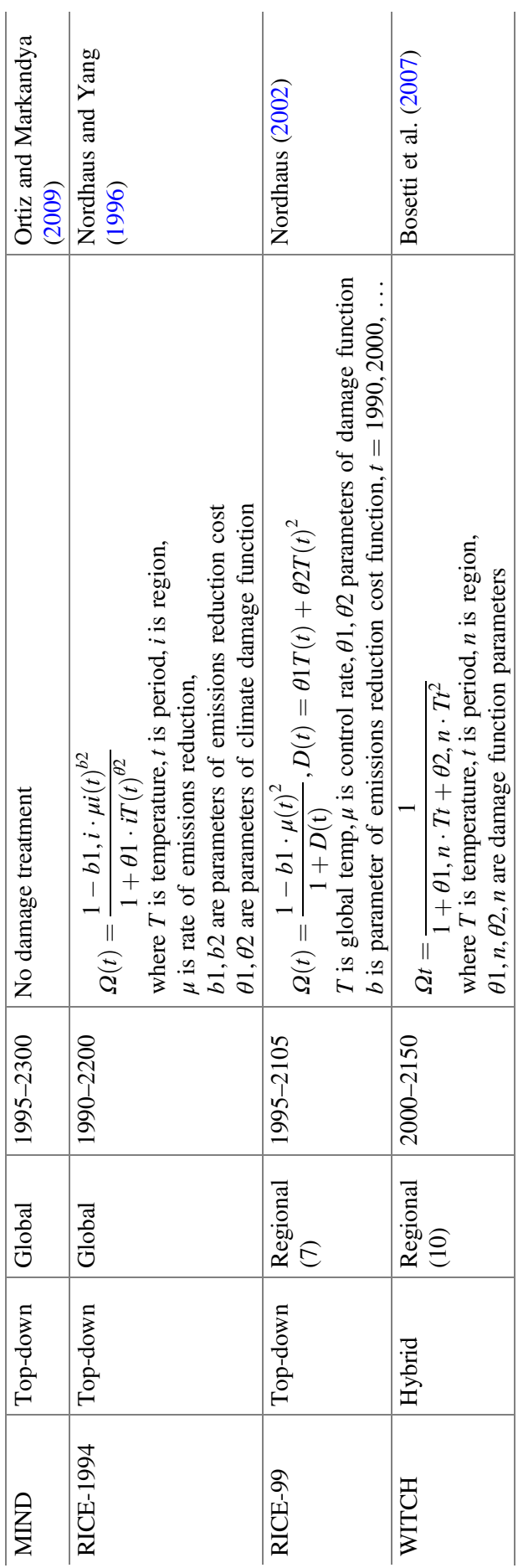


and accordingly ranks different consumption paths. Welfare is increasing in per capita consumption for each generation but with diminishing marginal utility of consumption. The more you consume (or the wealthier you are), the less valuable an additional unit of consumption is. If we expect future generations to be wealthier, then additional consumption for them is less valuable than it is for us. Two central normative parameters determine the relative importance given to different generations. The pure rate of time preferences is a subjective weighting of consumption at different times, and a positive value means that immediate consumption is valued more than future consumption. Higher values increase the bias towards present consumption. The elasticity of the marginal utility of consumption is a measure of how many additional units of consumption fall in value in terms of utility. For a given growth in consumption over time, higher elasticity means that an additional unit of consumption is more valuable today than in the future.

The overall savings rate for physical capital and the rate of control of emissions of greenhouse gases are the two key decision variables for the economy. A single commodity can be either consumed or invested. Consumption viewed broadly includes food and shelter as well as environmental amenities and services. The production of output is represented by a Cobb-Douglas production function in capital, labour and energy. Energy can come from carbon-based fuels or noncarbon-based technologies. Technological change can come from economy-wide technological change or carbon-saving technological change.

The key feature that turns the neoclassical growth model into a fully integrated assessment model is the linking of certain geophysical relationships affecting climate change to the economy: the carbon cycle, a radiative forcing equation, climate change equations and a climate-damage relationship. In the DICE-2007 model, industrial $\mathrm{CO}_{2}$ emissions constitute the only GHG that can be controlled and vary with total output, a time-varying emissions-output ratio and a rate of control of emissions. The cost of tougher climate policies will be reflected in reductions in output. A radiative forcing equation calculates the impact of GHG accumulation on the radiation balance of the globe. The climate equations that draw from general circulation models calculate the mean surface temperature of the globe and the average temperature of the deep oceans. The climate-damage relationship translates climate change into economic damages by drawing on estimates of economic impacts from other work.

Regarding technology, all optimal growth models among those reviewed assume exogenous (induced) technological change (ITC), while most also incorporate parameters that are endogenously approached (endogenous technological change-ETC); the only exception appears to be the WITCH model, in which technology is exclusively changed endogenously (Table 4). In contrast to DICE, in the latest DICE-2007 model (Nordhaus 2008), both forms of technological change are exogenous, which can be perceived as a serious limitation, especially as changes in carbon prices would be expected to induce carbon-saving technological change.

As suggested in Table 4, uncertainty in optimal growth models is usually treated deterministically, in their original design; only DICE applications have treated uncertainty in a probabilistic manner, by means of Monte Carlo analysis 


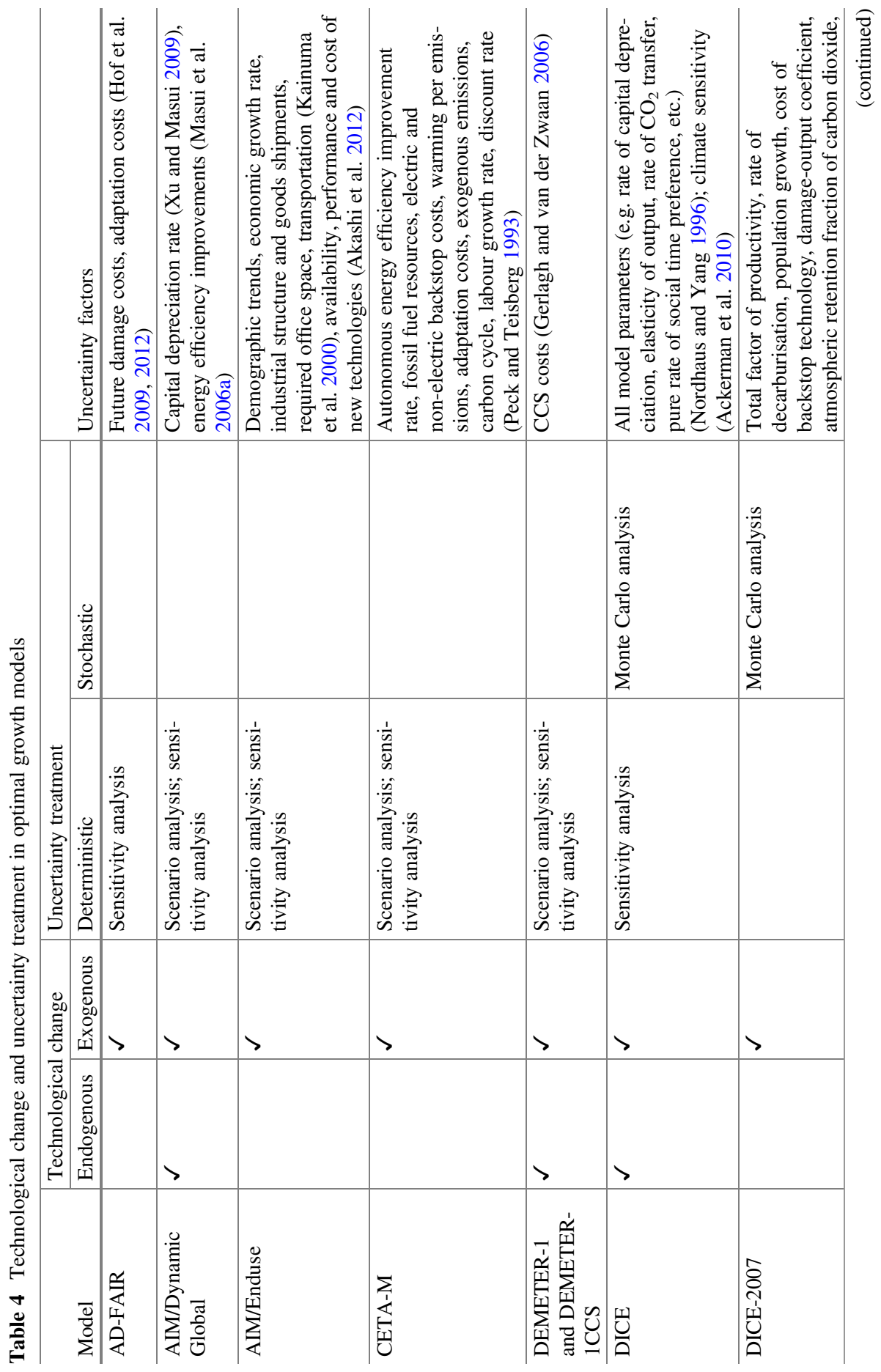




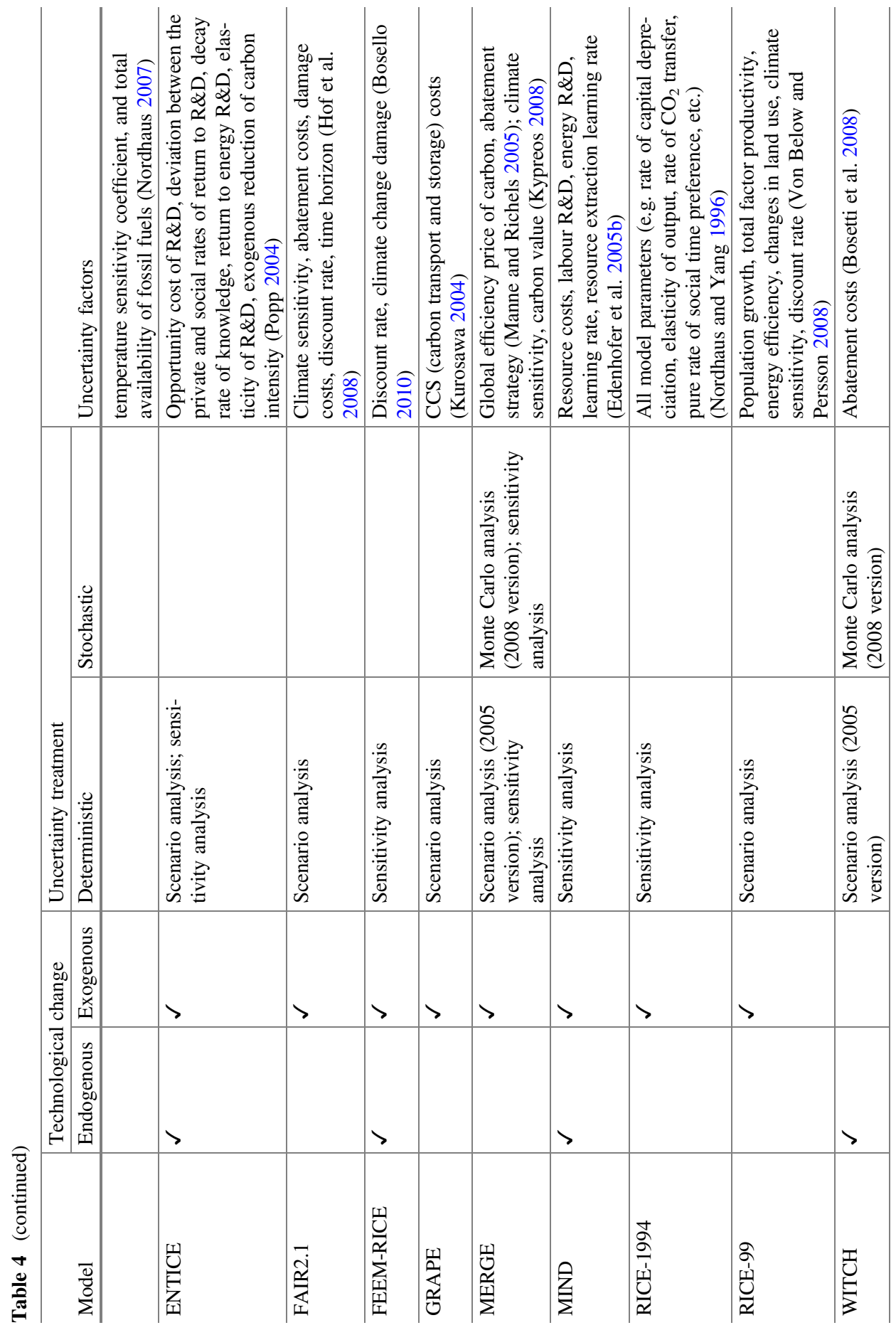


(e.g. Nordhaus 2007; Ackerman et al. 2010). Furthermore, the MERGE and WITCH integrated assessment models were upgraded in their 2008 versions so as to include Monte Carlo analysis in treating uncertainty.

\section{Computable General Equilibrium Models}

This section draws heavily on Wing's lucid presentation of the basic structure of all computable general equilibrium models used for economy-environment interactions (Wing 2011). CGE models are an algebraic representation of the intricate functioning of a market economy and are based on the core abstract theoretical foundation of how a decentralised price system works. Demand and supply for goods arise from consumers maximising utility and producers maximising profits, with prices bringing about equilibrium in the markets. What makes them "computable" models is the use of economic data to derive numerical parameters that will simulate the real world when solved for equilibrium prices, demand and supply levels of goods. National Accounts for a specific year provide the requisite information on expenditures for goods and services by production sectors and households, as well as the division of factors of production across producers. Data is also required to determine the price elasticities of demands and supplies and factor substitution. This data is usually derived from other empirical work analysing how the behaviour of agents responds to price changes. With the use of National Accounts and elasticity data, the parameters of CGE equations are "calibrated" so that the equilibrium solution of the numerical model precisely reproduces the data of a real economy for a given year.

The general way that CGE models are used for policy analysis is to change one or more of the exogenous parameters of the economy and compute the new equilibrium. Comparing the new counterfactual equilibrium to the initial equilibrium vectors of prices and activity levels as well as the level of utility of the representative household provides insights about the effect of a "shock" on the economy.

By modelling the linkages between the different sectors of an economy, CGE models are able to capture not only the direct impacts of a policy on one sector of the economy but to trace its full (or general equilibrium) impact on the interdependent sectors of an economy and ultimately the change in consumption (or utility) of the representative agent, which is a measure of the welfare impact. A carbon tax will not just increase the cost of certain forms of energy but will also affect the demand and supply of other goods. This is one of the main advantages of these models relative to partial equilibrium models that focus on a single sector or other models that do not have a detailed multi-sector representation of the economy. For example, neoclassical growth models that model the economy as a single sector cannot capture these general equilibrium effects, despite focusing on a broader understanding of longterm dynamics. An overview of the reviewed CGE models can be found in Table 5.

CGE models have traditionally focused on evaluating the costs of emission reductions, alternative mitigation policies and the damages resulting from climate change. Increasing attention is also given to considering the costs and benefits of 
Table 5 Overview of computable general equilibrium models

\begin{tabular}{l|l|l|l}
\hline Model & Model perspective & Regions & Forecasting period \\
\hline AIM & Top-down & Regional (21) & $1990-2100$ \\
\hline AIM/Material & Top-down & Japan & $1995-2010$ \\
\hline Dynamic GTAP & Top-down & Global & $1997-2025$ \\
\hline G-CUBED & Top-down & Regional (8) & $2000-2100$ \\
\hline GEM-E3 & Top-down & Regional (Europe) & $1996-2020$ \\
\hline GREEN & Top-down & Global & $1985-2050$ \\
\hline GTAP-E & Top-down & Regional (5) & \\
\hline GTEM & Top-down & Global & $1997-2100$ \\
\hline ICES & Top-down & Regional (14) & $2001-2050$ \\
\hline IGEM & Top-down & Regional (USA) & $2000-2060$ \\
\hline IMACLIM-R & Top-down & Regional (5) & $1997-2100$ \\
\hline LINKAGE & Top-down & Global & $2004-2080$ \\
\hline MEMO & Bottom-up & National & $2010-2030$ \\
\hline MIRAGE & Top-down & Regional & $2004-2020$ \\
\hline MIT EPPA & Top-down & Regional (16) & $2000-2100$ \\
\hline MS-MRT & Hybrid & Regional (10) & $2000-2030$ \\
\hline SGM 2004 & Hybrid & Global (14) & $2000-2050$ \\
\hline WIAGEM & Top-down & Regional (25) & $2000-2050$ \\
\hline WORLDSCAN & Top-down & Regional (16) & $2000-2050$ \\
\hline
\end{tabular}

adaptation. A standard exercise is to examine the effect that a carbon tax will have on an economy's output and emissions of greenhouse gases. A multi-region model with international trade could examine how carbon tax policies would perform if different countries apply different tax rates (Elliott et al. 2010). A typical way of capturing the impacts of climate change on an economy in a CGE model is to model the shocks through several possible channels. Rising temperatures can lead to changes in consumer expenditure patterns such as an increase in demand for air conditioning in the summer or a drop in demand for heating in the winter. By introducing a shock parameter into the representative agent's expenditure function, this influence can be captured. To the extent that climate change reduces the productivity of space conditioning, the shock parameter rises, leading to increases in expenditure required for a given level of space conditioning and thus ultimately negatively impacting the households' welfare. In a similar fashion, shock parameters can be introduced to account for changes in the productivity of primary factors in various industries. If climate change reduces (or increases) the yield of certain crops, then a shock parameter can be changed to capture the reduced productivity in the agricultural sector. Comparing a benchmark equilibrium where the shock parameter has a unit value with a new equilibrium resulting from changed parameter values on agricultural productivity will give a measure of the welfare loss from this impact of climate change. Shock parameters can also be introduced to capture reductions in the aggregate endowments of capital and labour such as those arising from damage to property or from increased morbidity or mortality. By appropriately incorporating a 
full set of possible climate change impacts through relevant shock parameters, the computable general equilibrium model is able to tally the loss of welfare to the representative agent resulting from the several productivity shocks. This method, however, does not capture impacts that do not register in markets such as loss in biodiversity or an increase in risk of morbidity and mortality.

Technological change and uncertainty treatment are presented in Table 6. In this domain, CGEs appear similar to optimal growth models, in that they mostly feature induced technological change, although GEM-E3, IGEM, IMACLIM-R and MIT EPPA also have technological aspects endogenously determined, and in that they all treat uncertainty by means of scenario or deterministic sensitivity analyses. The only exception in CGE modelling applications in the literature appears to be the MIT EPPA model, in which anthropogenic emissions of greenhouse gases and precursors were sampled with Monte Carlo analysis (Webster et al. 2002, 2003).

Since the economy in CGE models is always at an optimum, any restrictions on GHGs necessarily lead to costs or losses in output. No regrets or double dividends are possible in these models; this contrasts with some macroeconometric models discussed in Sect. 7. DeCanio (2003) carries out a detailed, fundamental critique on the underlying theoretical basis of CGE models.

\section{Partial Equilibrium Models}

Partial equilibrium analysis differs from general equilibrium modelling primarily by focusing on a specific market or sector and assuming that prices (or conditions) in the rest of the economy remain constant or unchanged. It is usually justified theoretically when the changes being considered affect primarily one market and are expected to have a relatively small impact on the rest of the economy. Partial equilibrium analysis is used extensively to estimate the impacts of climate change in different sectors of the economy. Although partial equilibrium analysis is unable to capture the broader implications that climate impacts or mitigation will have as sector changes reverberate through all economic sectors, it has the advantage of providing a more detailed understanding compared to a general equilibrium appraisal, which can be very useful in designing policy.

One of the early applications of partial equilibrium analysis to assess the impacts of climate change was on the agricultural sector. Two distinct ways to measure the impact of climate change on agriculture have emerged: a statistical approach and a biophysical approach. Mendelsohn et al. (1999) used the biophysical approach to estimate damages to the agricultural sector in the USA: simulation models were used to predict changes in yield from crop (damage function), and then these provided the inputs for a spatial partial equilibrium model of the US agricultural sector. Much like their general equilibrium counterparts, this shift in the parameter of a production function that would result from climate change brings about a new equilibrium, and the difference in welfare is a measure of the economic damage caused. 


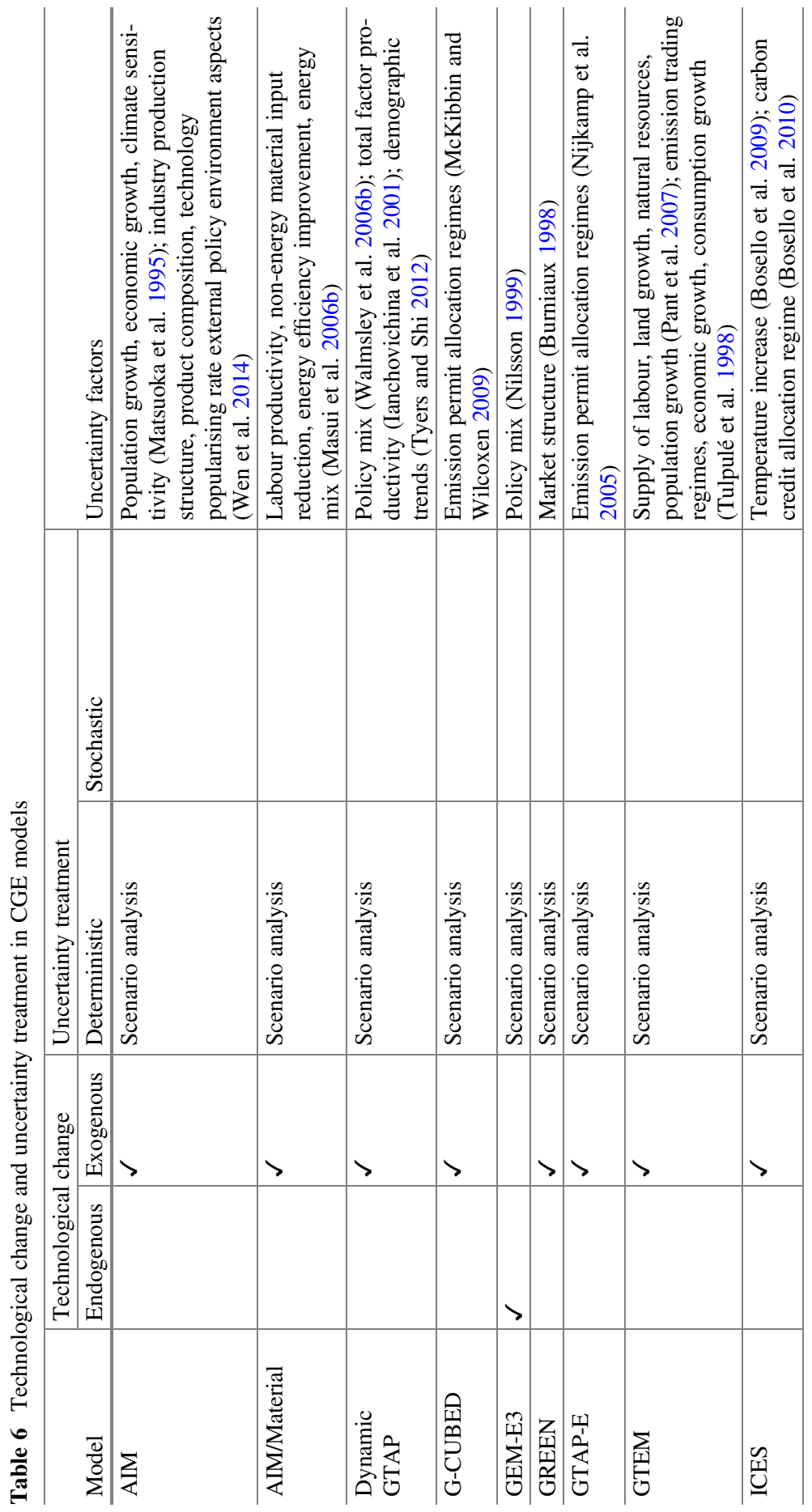




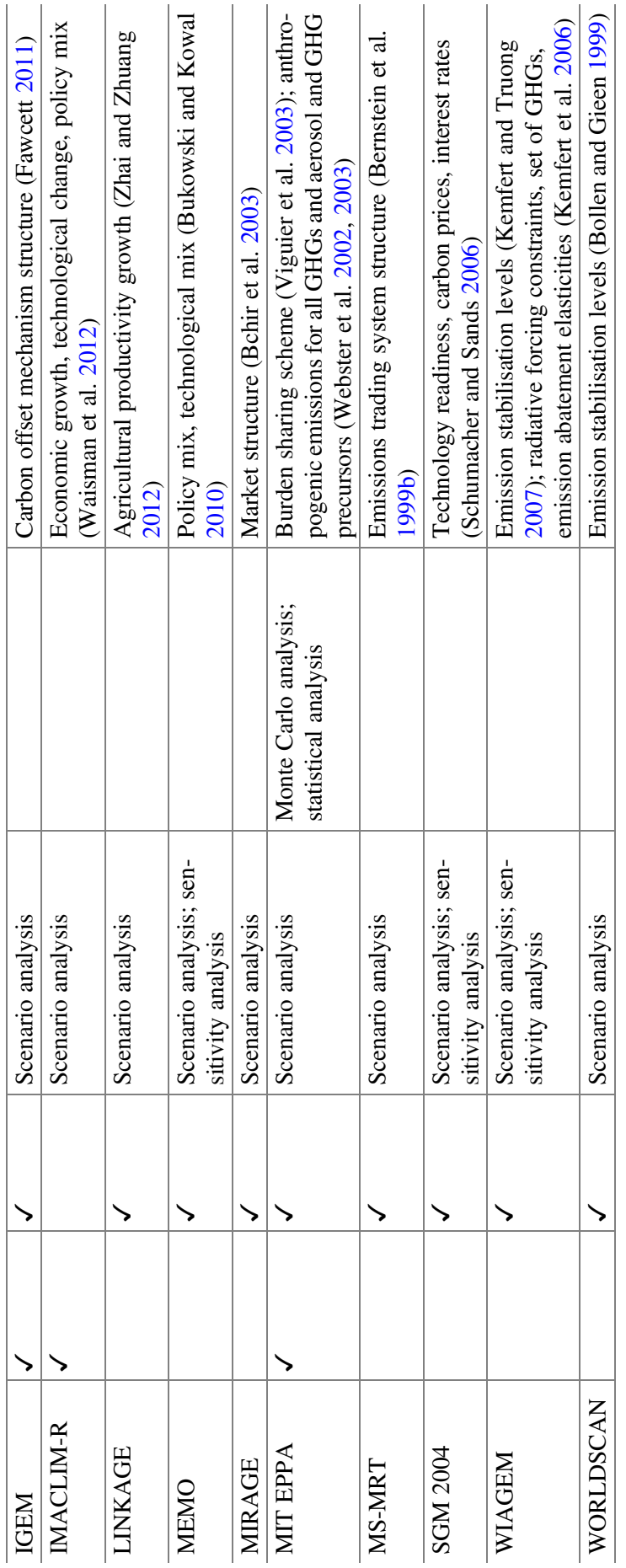


Producers' costs are a function of the outputs of the goods they produce, factor prices and exogenous environmental inputs like climate, soil quality, air quality and water quality. In the statistical approach, land is separated from other production inputs and considered to be heterogeneous with different environmental characteristics. Perfect competition for land is assumed which implies that entry and exit will drive pure profits to zero. In this case land value should be equal to the net revenue from the land, which is linked to the value of land. This "Ricardian" model allows one to measure the impact of a change in an environmental variable through the impact on the value of land. A change in an environmental factor that damages production will lead to a fall in the stream of future of land rents and in the value of land. If prices for all markets (except that of land) are assumed constant, the value of the environment change is captured by the change in aggregate land values. In order to discern the impact of climate variation (as well as mean temperature) on property values, Mendelsohn et al. (1999) used cross-sectional data on aggregate land values in different counties along with 12 climatic variables (of temperature and precipitation). They then regressed aggregate farm values on climate, soil and economic variables in order to determine the marginal impact of each climate variable. Essentially, differences in temperature and weather patterns at a point in time across various regions were used to project climate change impacts in the future.

Both biophysical and statistical partial equilibrium approaches have been used to estimate impacts of climate change across multiple sectors of an economy. With consistent assumptions across sectoral analyses, these are often added up to provide a value of total impact to an economy. This total value does not capture non-market impacts such as health and biodiversity.

The idea of drawing on the literature of biophysical models to find the physical climate impacts for different sectors and then translate these into monetary values by various methods (first order calculations, partial equilibrium models, and guesstimates) and add them up to find a total monetary value of "damages" from climate change is also known as the "enumerative approach". This is probably one of the easiest methods to grasp conceptually as the move from the physical to the monetary valuation is more transparent. Estimates of "physical effects" of climate change on specific sectors of the economy or environmental services are obtained from natural science work (climate models, impact models and laboratory experiments). Economic valuation methods are then used to place a monetary value on the physical impact, and this can either provide an estimate of damage to a specific sector like agriculture, or the values of damages to the different sectors (tourism, agriculture, forestry, biodiversity, etc.) can be added up to give an estimate of the total damages of climate change to a region. For instance, engineering estimates can be used to find the physical effect that a rise in sea level has on coastal protection and loss of land. Economic estimates of the cost of coastal protection and the value of lost land or land protection follow. For goods that are not traded in markets, like climate impacts to health and biodiversity, other economic techniques are needed to estimate monetary values. Physical loss to health could be translated into monetary terms by considering medical expenses, productivity loss or citizens' willingness to pay to avoid risk of health damages (Tol 2010). 
Theory does not suggest that adding up the separate economic sectoral impacts will lead to the same result as evaluating total climate change impacts with a computable general equilibrium or macroeconomic model that incorporate all market interactions. A particularly stark example of the importance of capturing market interactions can be found in the literature on what is known as the "rebound effect" (Sorrell 2009). Improvement in energy efficiency might be expected to directly lead to reductions in energy consumption and GHG emissions, and many policies to improve energy efficiency have that aim. An analysis that looks just at the immediate impact of energy efficiency or savings policy might lead to that conclusion. However, empirical and theoretical literature show that there can often be a rebound effect such that any gains in energy efficiency are countered by increases in energy consumption. This could happen because the improved energy efficiency brings about a fall in the price of energy leading to increased use of energy or the development of new energy-using products.

The more detailed analysis and quantification of damage functions that are part of the partial equilibrium studies or enumerative approaches have also been used as inputs into general equilibrium models; for example, Jorgenson et al. (2004) use sectoral damage functions as inputs into their Intertemporal General Equilibrium Model (IGEM). This distinguished their approach from many computable general equilibrium models that did not rely on damage functions derived from more detailed empirical sectoral studies. A damage function is used to describe how unit costs or the supply of input factors changes as a result of climate variation. For instance, for the sectors of crop agriculture, forestry, energy and water, a damage function is used in order to relate the percentage change in unit production costs to changes in temperature and precipitation. The difference between the unit price of producing a given quantity before and after the impact of climate change is used in the model to reflect the change in productivity or inputs required to produce the same amount of a good. This productivity change is incorporated in the relevant sector of the CGE to model the full economic implications of the climate impacts.

The three partial equilibrium models reviewed are presented in Table 7 . It is obvious that technological change differs across the three models, all of which are of global coverage. Only the GCAM model (formerly known as MiniCAM) features both endogenous and induced technological progress as well as characteristics of both bottom-up and top-down approaches (Urban et al. 2007), and, contrary to GIM and TIAM-ECN, there have been applications featuring uncertain parameters treated stochastically by means of Monte Carlo analysis (Scott et al. 1999).

One of the advantages of a sectoral approach is that it allows a much more detailed understanding of the various climate impacts and a more refined estimation of specific impacts on parts of the economy. One recent study known as PESETA (Ciscar et al. 2009) combined sectoral and computable general equilibrium models to produce a Europe-wide analysis of climate impacts for five categories: agriculture, tourism, river floods, coastal systems and health. The study pointed to the disadvantages of other regional integrated assessment studies that rely on reduced-form damage functions relating global temperature to GDP (as most wealth maximising IAMs do). Specifically, these reduced-form damage functions are often based on 
Table 7 Overview of partial equilibrium models, including uncertainty treatment and technological change

\begin{tabular}{l|l|l|l}
\hline Model & GIM & MiniCAM/GCAM & TIAM-ECN \\
\hline $\begin{array}{l}\text { Model } \\
\text { perspective }\end{array}$ & Top-down & Hybrid & Bottom-up \\
\hline Regions & Global (178) & Global (14) & Global (36) \\
\hline $\begin{array}{l}\text { Forecasting } \\
\text { period }\end{array}$ & $1990-2100$ & $1990-2100$ & $2010-2100$ \\
\hline $\begin{array}{l}\text { Technological } \\
\text { change }\end{array}$ & Endogenous & Endogenous; exogenous & Exogenous \\
\hline $\begin{array}{l}\text { Uncertainty } \\
\text { treatment }\end{array}$ & $\begin{array}{l}\text { Deterministic (sce- } \\
\text { nario analysis) }\end{array}$ & $\begin{array}{l}\text { Deterministic (scenario analysis); } \\
\text { stochastic (Monte Carlo analysis) }\end{array}$ & $\begin{array}{l}\text { Deterministic } \\
\text { (scenario } \\
\text { analysis) }\end{array}$ \\
\hline $\begin{array}{l}\text { Uncertainty } \\
\text { factors }\end{array}$ & $\begin{array}{l}\text { Climate prediction } \\
\text { models (Mendelsohn } \\
\text { and Williams 2004) }\end{array}$ & $\begin{array}{l}\text { Policy mix, emissions, atmo- } \\
\text { spheric concentration, radiative } \\
\text { forcing, global mean temperature } \\
\text { and climate sensitivity, damages } \\
\text { for the no intervention case, cost } \\
\text { of stabilising emissions, cost of } \\
\text { stabilising the atmosphere, cost of } \\
\text { stabilising the climate (Scott et al. } \\
\text { 1999) }\end{array}$ & $\begin{array}{l}\text { Radiative forcing } \\
\text { levels (van der } \\
\text { Zwaan et al. } \\
\text { 2013) }\end{array}$ \\
\hline
\end{tabular}

literature that draws on different and possibly inconsistent climate scenarios; only average temperature and precipitation are used rather than a fuller set of climate variables at an appropriate time-space resolution, resulting in estimates of impacts not having a detailed enough geographical resolution. In contrast, PESETA followed an enumerative (bottom-up) approach, which means that the impact assessment was based on much more detailed sectoral models deriving from the regions under study. In order to meaningfully add these impacts up, common climate scenarios were used at a high time-space resolution. Finally, the impacts derived from each sector were fed into a computable general equilibrium model (GEM-E3) allowing for the assessment of impacts, after market interactions had been incorporated. Another recent example of a national climate change assessment combining a sectoral approach with a top-down CGE can be found in the Garnaut Climate Change Review (Garnaut 2008).

\section{Energy System Models}

While much of the discussion on partial equilibrium models (Sect. 5) focused on ways of estimating damages that climate change may cause, energy system models focus on the key sector determining GHG emissions and costs arising from emission reduction policies. Numerous models have been developed over the years to provide energy policy guidance and that have evolved into integrated assessment models or 
components of IAMs. The analysis of energy and environmental policy often demands a level of technological explicitness and detail that goes beyond macroeconomic models that do not differentiate technology stocks. A class of technologyoriented models known as "bottom-up" models emerged in the 1970s (following the first oil crisis) and are still being developed, for the purpose of addressing this need for detail. While these were developed for energy resource planning purposes and began with simple, single-sector accounting tools, they soon evolved into complex and dynamic optimisation and simulation frameworks for energy and climate policy appraisal at local, national or international levels (Greening and Bataille 2009). As Mundaca et al. (2010) note, these models are disaggregated representations of the energy-economy system, entailing detailed characterisations of existing and new energy technologies, and can simulate alternative technological pathways. Besides considering least-cost means of achieving emission targets, these models are employed towards identifying a number of climate-energy issues, including best technology opportunities, costs of alternative mitigation policies and the potential for greater energy efficiency.

Energy system models can broadly be classified as optimisation models or simulation models. Optimisation models use information on costs and constraints of technology characteristics to identify the "best", "least-cost" or "optimal" technology. The consumer is assumed to be rational, and energy supplies are allocated to energy demands, based on minimum lifecycle technology costs. By incorporating a constraint on emissions, an optimisation model can estimate the least costs of achieving a target. Simulation models are designed to capture technological and economic dynamics as realistically as possible. Rather than seeking to find a leastcost solution, they model the most probable responses to policy shocks. Producers and consumers may carry out production and consumption activities with different objectives in contrast to optimisation models that usually operate from the perspective of a single optimising decision-maker. There are many simulation models of various degrees of sophistication. A sequential iterative simulation process is used to find an equilibrium set of prices and demands. A policy application affects prices, and the iterations continue until a new equilibrium is found. Outcomes are very sensitive to the dynamics and technologies assumed. A simulation, for instance, of a GHG policy will lead to very different results if carbon capture and storage or other backstop technologies are included. Table 8 presents an overview of the reviewed energy system models, along with their system, geographical and time coverage, mathematical structure and perspective.

The technological explicitness and detail of energy system models allow them to consider such issues as how policies can promote technology commercialisation and diffusion, but they have been criticised for lacking microeconomic (or behavioural) realism and "macroeconomic completeness" (or feedbacks). In terms of behavioural realism, they have been criticised for being too optimistic on the profitability of attaining energy efficiency from the diffusion of low-emission or inexpensive technologies. Part of the problem is that bottom-up models focus mostly on the financial costs while not taking into account such key factors as greater risks, intangible costs and longer payback periods associated with investments in energy 
efficiency. For instance, two light bulbs that may appear to provide the same service in terms of lumens may differ in risk of premature failure, payback period, shape, hue of light or time it takes for a bulb to reach full intensity; similarly, public transit and single-occupancy vehicles may provide the same personal transportation service, but evidence suggests that some consumers perceive public transportation as being of lower convenience, status and comfort level. By incorporating more parameters to gauge for consumers preferences, like time preferences or perception of risks, models will be better able to explain and predict the potential uptake and diffusion of new technologies. Mundaca et al. (2010) review models that attempt to capture more of this behavioural realism for the analysis of energy efficiency policies.

Being essentially partial equilibrium models focusing on energy consumption, energy system models tend to find relatively low mitigation costs because they only consider the impact of emission reduction strategies on energy system costs usually ignoring feedback loops and interactions with other sectors of the economy; exceptions of such models including feedback loops, however, can be found in the literature (e.g. Karkatsoulis et al. 2017). For instance, these models assume that investments within the energy sector can be funded at a constant rate of interest. An ambitious climate policy, however, would lead to a depreciation of capital stocks in certain sectors and accordingly change the return on investment in the energy sector as well as a concomitant reallocation of investments across sectors. These investment dynamics are a critical determinant of macroeconomic costs missed by the partial equilibrium analysis. For the same reason, most energy system models tend to neglect the potentially significant rebound effects and crowding-out implications of investments (Edenhofer et al. 2006).

As Table 8 suggests, all energy system models are bottom-up; exceptions include hybrid models (Greening and Bataille 2009) that also feature characteristics of top-down approaches, like MESSAGE and WEM (Urban et al. 2007), and economic engineering models in particular, combining microeconomic foundations of behaviour with technology details (such as DNE21+, NEMS, POLES and PRIMES). In a broader perspective, there are numerous ways that bottom-up models have added macroeconomic components, whether these derive from optimal growth models, macroeconomic models or computable general equilibrium models. Because of the technological explicitness of bottom-up models, the top-down feedbacks have focused on direct adjustment effects on the demand for energy-using goods and services in response to changes in the cost of delivery, but do not capture the secondary macroeconomic effects like change to wages, cost of capital, exchange rates and government budgets resulting from energy price changes. When governmental energy policies are moderate in scope, they are unlikely to have substantial macroeconomic implications, but as policies become more ambitious - as would be required for a rapid reduction in GHG emissions or a big shift towards renewable energy sources - the macroeconomic consequences constitute an important factor in assessing the policy outcomes (Greening and Bataille 2009).

Just as bottom-up models have been trying to overcome their weaknesses by combining elements of top-down models, there have been many attempts by 
Table 8 Overview of energy system models

\begin{tabular}{|c|c|c|c|c|c|}
\hline Model & $\begin{array}{l}\text { System } \\
\text { coverage }\end{array}$ & $\begin{array}{l}\text { Mathematical } \\
\text { structure }\end{array}$ & $\begin{array}{l}\text { Model } \\
\text { perspective }\end{array}$ & Regions & $\begin{array}{l}\text { Forecasting } \\
\text { period }\end{array}$ \\
\hline Calliope & $\begin{array}{l}\text { Partial } \\
\text { equilibrium }\end{array}$ & Optimisation & Bottom-up & National & \\
\hline DNE21+ & $\begin{array}{l}\text { Limited macro } \\
\text { feedback }\end{array}$ & Optimisation & $\begin{array}{l}\text { Economic } \\
\text { engineering }\end{array}$ & $\begin{array}{l}\text { Regional } \\
(77)\end{array}$ & $2000-2100$ \\
\hline EFOM & $\begin{array}{l}\text { Partial } \\
\text { equilibrium }\end{array}$ & Optimisation & Bottom-up & National & 1974-2020 \\
\hline ERIS & $\begin{array}{l}\text { Partial } \\
\text { equilibrium }\end{array}$ & Optimisation & Bottom-up & $\begin{array}{l}\text { Regional } \\
(12)\end{array}$ & 1990-2050 \\
\hline GENIE & $\begin{array}{l}\text { Limited macro } \\
\text { feedback }\end{array}$ & Optimisation & Bottom-up & $\begin{array}{l}\text { Regional } \\
\text { (4) }\end{array}$ & 1995-2050 \\
\hline GET-LFL & $\begin{array}{l}\text { Partial } \\
\text { equilibrium }\end{array}$ & Optimisation & Bottom-up & Global & $2000-2050$ \\
\hline $\begin{array}{l}\text { MARKAL/ } \\
\text { TIMES }\end{array}$ & $\begin{array}{l}\text { Partial } \\
\text { equilibrium }\end{array}$ & Optimisation & Bottom-up & $\begin{array}{l}\text { Regional } \\
(5)\end{array}$ & 1990-2050 \\
\hline MEDEE 2 & $\begin{array}{l}\text { Partial } \\
\text { equilibrium }\end{array}$ & Simulation & Bottom-up & National & 1990-2040 \\
\hline MESSAGE & $\begin{array}{l}\text { Partial } \\
\text { equilibrium }\end{array}$ & Optimisation & Hybrid & $\begin{array}{l}\text { Regional } \\
\text { (11) }\end{array}$ & $2005-2100$ \\
\hline NEMS & $\begin{array}{l}\text { Limited macro } \\
\text { feedback }\end{array}$ & $\begin{array}{l}\text { Market } \\
\text { equilibrium }\end{array}$ & $\begin{array}{l}\text { Economic } \\
\text { engineering }\end{array}$ & $\begin{array}{l}\text { National } \\
\text { (USA) }\end{array}$ & $2000-2030$ \\
\hline POLES & $\begin{array}{l}\text { Partial } \\
\text { equilibrium }\end{array}$ & $\begin{array}{l}\text { Market } \\
\text { equilibrium }\end{array}$ & $\begin{array}{l}\text { Economic } \\
\text { engineering }\end{array}$ & $\begin{array}{l}\text { Regional } \\
(18)\end{array}$ & $1980-2100$ \\
\hline PRIMES & $\begin{array}{l}\text { Partial } \\
\text { equilibrium }\end{array}$ & $\begin{array}{l}\text { Market } \\
\text { equilibrium }\end{array}$ & $\begin{array}{l}\text { Economic } \\
\text { engineering }\end{array}$ & $\begin{array}{l}\text { Regional } \\
\text { (Europe) }\end{array}$ & $2005-2050$ \\
\hline WEM & $\begin{array}{l}\text { Limited macro } \\
\text { feedback }\end{array}$ & Optimisation & Hybrid & $\begin{array}{l}\text { Regional } \\
(25)\end{array}$ & $2015-2040$ \\
\hline
\end{tabular}

top-down modellers to enhance their technological explicitness by incorporating elements of bottom-up models. Technological change has generally been captured in top-down models with the use of two key parameters: elasticity of substitution (ESUB) and the autonomous energy efficiency index (AEEI). ESUBs are used to capture the degree to which a relative price change will affect the substitution between any two pairs of aggregate inputs (capital, labour, energy, materials) and between different forms of final energy. In general, the easier it is to substitute capital for energy or one form of energy for another, the lower the cost of reducing energy use or GHG emissions. AEEI gives the rate at which price-independent technological evolution improves energy productivity, and itself depends on changes in technology and capital stock turnover. A higher AEEI means that the economy becomes energy-efficient faster. ESUB and AEEI are often estimated from aggregate, historical data, but these may not be good indicators for future values under different policy regimes. A policy focus on low to zero GHG emissions may have a substantial impact on AEEI and ESUB that is not captured by looking into the past. This inadequacy of top-down models partly explains the push towards greater 
technological detail and making technological change endogenous. Another reason is that top-down models represent technological change as an abstract, aggregate phenomenon which may be adequate to assess economy-wide instruments like taxes and tradable permits but are unable to consider technology-focused policies. There are several different ways of incorporating elements of bottom-up models into top-down models, but there are limitations to how much technological detail can be incorporated without running into computational and other difficulties.

Technological change along with uncertainty treatment in the reviewed energy system models is presented in Table 9. It is evident that there exists a balance between endogenous and exogenous technological change among energy system models. Uncertainty treatment, however, is again treated mostly by means of deterministic approaches, i.e. scenario and sensitivity analysis, with the most prominent exception being that of the MARKAL/TIMES model, which also features Monte Carlo analysis according to Seebregts et al. (2002).

There exist a large number of general reviews of existing energy system models (e.g. Worrell et al. 2004; Jebaraj and Iniyan 2006), while Mundaca et al. (2010) provide a review of models with a specific focus on energy efficiency, also identifying a separate category of models called "accounting models".

It should be noted that energy system models can be perceived as a cross-cutting category of models based on this classification, ranging from partial equilibrium to neoclassical/optimal growth models. In essence, they are partial equilibrium models, assuming equilibrium in one particular sector, i.e. the power sector. However, this category also includes models with features from other modelling approaches and structures, as shown in Table 8. For example, GET-LFL is an energy system model that can be classified as a cost minimisation IAM (Wei et al. 2015). The same applies for DNE21+, MIND and MESSAGE (Stanton et al. 2009). Furthermore, it should be mentioned that energy system models do note solely focus on the power sector but all economic sectors that are consumers of energy. For example, they are also used in studies oriented on the transport sector (e.g. Siskos et al. 2015). The latter is responsible for around $25 \%$ of energy-related GHG emissions today and is widely acknowledged to be the most inflexible sector of the energy system with regard to deep emissions reduction in the future (e.g. Hickman et al. 2010).

\section{Macroeconometric Models}

Environmental policy issues around 1990 pushed the development of computable general equilibrium models like the GREEN model of OECD, while in Europe, there was a parallel development of the CGE model GEM-E3 and the input-output econometric (or macroeconometric) model E3ME, which integrated energy and emissions in the economic model. E3ME stands for energy-environment-economy (E3) multisectoral model at the European level and, along with its variants, remains one of the most prominent macroeconometric models for appraisal of climate policy and climate-economy interactions. E3MG is a similar model that focuses on the 


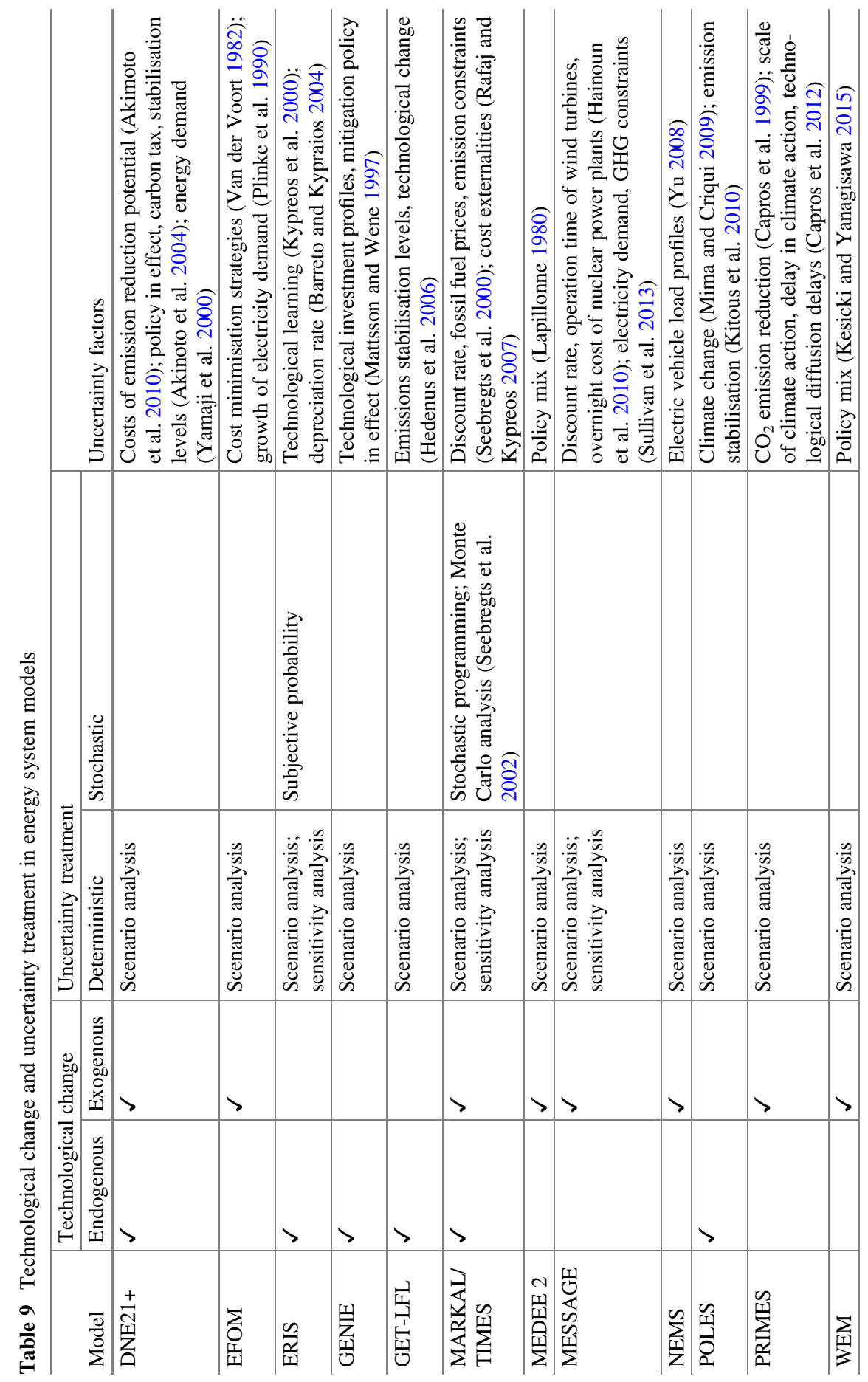


global level, as does the Oxford Global Macroeconomic and Energy Model, while the MDM-E3 model focuses on the UK economy (Table 10).

Macroeconometric models are "integrated" or hybrid in that they combine top-down macro models with bottom-up energy system models. The goal of integrating the two types of models is to provide a dynamic, non-linear picture of economic change in a detailed interindustry framework (West 2002). While static models can measure long-run comparative equilibrium solutions, the macroeconometric models are able to track the time path of the economy through

Table 10 Overview of macroeconometric models, including uncertainty treatment and technological change

\begin{tabular}{|c|c|c|c|c|}
\hline Model & E3ME & E3MG & MDM-E3 & $\begin{array}{l}\text { Oxford global } \\
\text { macroeconomic } \\
\text { and energy } \\
\text { model }\end{array}$ \\
\hline $\begin{array}{l}\text { Model } \\
\text { perspective }\end{array}$ & $\begin{array}{l}\text { Hybrid (Cam- } \\
\text { bridge Economet- } \\
\text { rics 2014): } \\
\text { top-down } \\
\text { (energy); bottom- } \\
\text { up (electricity } \\
\text { supply) }\end{array}$ & $\begin{array}{l}\text { Hybrid (Barker } \\
\text { and Scrieciu } \\
\text { 2010): top-down } \\
\text { (interactions, } \\
\text { feedback and } \\
\text { spillover effects } \\
\text { between the } \\
\text { required invest- } \\
\text { ments and out- } \\
\text { comes and the rest } \\
\text { of the economy); } \\
\text { bottom-up } \\
\text { (energy technol- } \\
\text { ogy model) }\end{array}$ & $\begin{array}{l}\text { Hybrid (Barker } \\
\text { et al. 2007): } \\
\text { top-down; bot- } \\
\text { tom-up (less } \\
\text { detailed electric- } \\
\text { ity sub-model, } \\
\text { energy technol- } \\
\text { ogy model) }\end{array}$ & Top-down \\
\hline Regions & Global (59) & Global (20) & National & Global (22) \\
\hline $\begin{array}{l}\text { Forecasting } \\
\text { period }\end{array}$ & 1990-2100 & $1971-2100$ & Until 2030 & $2005-2020$ \\
\hline $\begin{array}{l}\text { Technological } \\
\text { change }\end{array}$ & Endogenous & Endogenous & Exogenous & Exogenous \\
\hline $\begin{array}{l}\text { Uncertainty } \\
\text { treatment }\end{array}$ & $\begin{array}{l}\text { Deterministic } \\
\text { (scenario analy- } \\
\text { sis); stochastic } \\
\text { (probabilistic } \\
\text { analysis) }\end{array}$ & $\begin{array}{l}\text { Deterministic } \\
\text { (scenario analy- } \\
\text { sis); stochastic } \\
\text { (probabilistic } \\
\text { analysis) }\end{array}$ & $\begin{array}{l}\text { Deterministic } \\
\text { (scenario } \\
\text { analysis) }\end{array}$ & $\begin{array}{l}\text { Deterministic } \\
\text { (scenario } \\
\text { analysis) }\end{array}$ \\
\hline $\begin{array}{l}\text { Uncertainty } \\
\text { factors }\end{array}$ & $\begin{array}{l}\text { All model param- } \\
\text { eters (Mercure } \\
\text { et al. 2017); level } \\
\text { of coordination in } \\
\text { fiscal policies } \\
\text { (Barker 1998, } \\
\text { 1999) }\end{array}$ & $\begin{array}{l}\text { Policy mix, car- } \\
\text { bon prices, new } \\
\text { investments, } \\
\text { emissions trading } \\
\text { system structure } \\
\text { (Barker et al. } \\
\text { 2012); technology } \\
\text { penetration levels } \\
\text { (Dagoumas and } \\
\text { Barker 2010) }\end{array}$ & $\begin{array}{l}\text { Policy mix } \\
\text { (Barker et al. } \\
\text { 2007; Ekins and } \\
\text { Etheridge 2006) }\end{array}$ & $\begin{array}{l}\text { Policy mix, per- } \\
\text { mit trading sys- } \\
\text { tem structure } \\
\text { (Cooper et al. } \\
\text { 1999) }\end{array}$ \\
\hline
\end{tabular}


short-run disequilibrium adjustments. Macroeconometric models incorporate equations that trace the trajectory of national economic aggregates as well as related components of economic activity like labour, savings and consumption. These equations are estimated econometrically. Aggregate potential output is usually simulated as a function of aggregate inputs of capital and labour, and sometimes energy and materials. Transactions among economic sectors are described by inputoutput models. More or less aggregated sectoral demand functions are estimated by means of historical data, e.g. for energy services and food, allowing for projections of future trends in response to a carbon tax or other climate policies. The accuracy of these forecasts depends on the extent to which historical changes, e.g. technology changes induced by past price changes, are likely to be a good indicator for future changes.

Unlike CGE and optimal growth models, macroeconometric models do not assume that markets clear in the short and medium run, and demand and supply do not derive from optimising behaviour of consumers and producers. They are disequilibrium models with demand and supply approaching equilibrium in the long run. Because of the fact that they do not posit optimising behaviour on the part of agents or a "central planner", they are characterised as simulation models, representing as closely as possible the dynamics of the real world. The economy and energy system are described by a set of rules that need not lead to full equilibrium. Some macroeconometric models also allow for structural unemployment resulting from inadequate demand for labour in the long run (Hourcade et al. 1996). CGE models usually assume that there is no unemployment or that the labour market clears. The Post-Keynesian E3ME macroeconometric model estimates labour with various disaggregated equations, e.g. working hours are estimated for men and women, different ages and sectors, thus allowing the model to forecast fulltime and part-time workers. Disequilibrium in the labour market or unemployment is therefore a feature of this model. For this reason, it is sometimes argued that CGE models are more suitable for describing long-run steady-state behaviour, while macroeconometric models are more suitable for forecasting short-term outcomes. The parallel development of these "very different models" has given rise to an ongoing, often-heated discussion and conflicting positions between the input-output econometric and the CGE community (e.g. Grassini 2009). Robinson (2006) provides a nice account of the historical tension between CGE and macroeconometric models and the remaining theoretical difficulties of reconciling the approaches. Kratena and Streicher (2009) on the other hand attempt to better identify the key features differentiating the two approaches and suggest that the distance between them is much smaller than usually assumed.

One of the model outcomes that has often set the E3ME model apart from other top-down models is that it can give rise to negative costs, i.e. the imposition of climate policies can actually lead to increases in employment and output. Since structural unemployment is possible in this model, a transition to a low carbon economy can potentially enhance effective demand for labour reducing the lost output. In the E3MG model where the labour market and other markets may not clear, part of the impact of induced technological change arising from climate 
policies is to raise growth through increased transfer of labour from traditional to modern sectors (Edenhofer et al. 2006).

As many CGE models assume the economy is always at an optimum, including full employment, any "constraints" resulting from climate policies can only result in additional costs to the economy. In general, first best models assume perfect markets and optimal policy implementation so that no-regret options are impossible. Second best models essentially allow for the possibility that climate policies can reduce market imperfections as a side benefit. This way, the costs of climate protection can be diminished or even become negative. Although imperfections or second best modelling is a fundamental feature of most macroeconometric models, since many of these draw heavily on the Keynesian tradition, different kinds of imperfections are often incorporated in GCE models and are usually implicitly assumed in most bottom-up (engineering) energy sector models (Sect. 6). Double dividends arise because climate policy redresses one imperfection (missing market or other institutions for climate protection) while also potentially reducing other market imperfections, e.g. barriers that prevent uptake of new technologies. When incorporating side benefits, for example, from reducing "distortionary" taxes with revenue from a carbon tax, in second best models, it would help to consider whether climate policies are the best way of dealing with many market imperfections and the extent to which these benefits should be attributed to climate policy per se.

\section{Other Integrated Assessment Models}

Optimal growth and CGE models are both based on a specific long-standing theoretical foundation so that most of these models can be understood as variations (though sometimes substantial) on a theme and comparability seems to be more straightforward. This section presents models that are hard to classify into any of the previously discussed models and delves into one well-known non-CGE model, the PAGE2002 model, as indicative of the kind of possible departures from standard neoclassical growth, CGE and macroeconometric models. These models are presented in Table 11. It should be noted that FUND should not be considered as a hybrid model, but it can run different optimisation modes, including top-down or bottom-up, cooperative or non-cooperative and with or without interregional capital transfer.

The PAGE2002 model attracted much attention recently due to it being the top-down model that the Stern team relied on for many of the much publicised aggregate climate change damages. One of the features that made it attractive to the Stern team was the model's central focus on taking account of uncertainty in many of the climate-economy parameters. PAGE was developed as a computer simulation model in 1992 for use in decision-making within the European Commission. It was explicitly designed to be comprehensive but "accessible to policy makers" with the "simplest credible functional forms" (Hope et al. 1993), so that it remains transparent and able to run fast and repeatedly using a random sample of uncertain input 


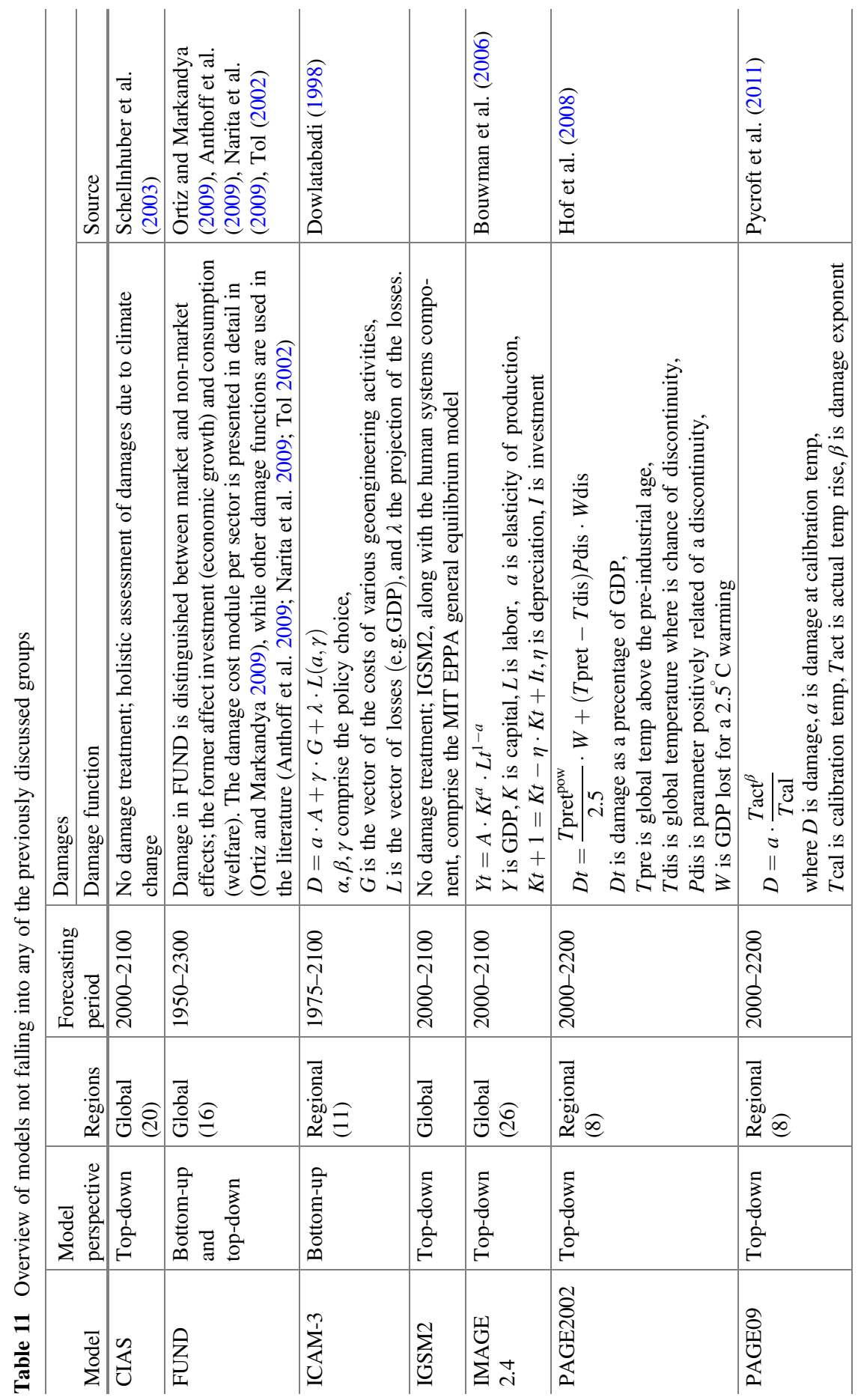


parameters (Plambeck et al. 1997). A common criticism of IAMs is that they are so complex and opaque ("black box") that it is hard to see how the various underlying assumptions affect their outcomes. The use of simple equations to capture complex climatic and economic phenomena is, according to Hope (2006), justified because the results approximate those of the most complex climate simulations and all aspects of climate change are subject to profound uncertainty. Uncertainty is a central focus of the model that builds up probability distributions of the results by representing the key inputs to the marginal impacts with probability distributions (stochastic treatment). An approximate probability distribution is generated for the model outputs of temperature rise, climate change damages and costs of adaptation and prevention. This is meant to help decision-makers perform a risk analysis so that they can select a policy that balances the cost of intervention against the benefits of mitigating potential climate change impacts (Plambeck et al. 1997).

A full description of the PAGE2002 model and all of its equations can be found in Hope (2006). A number of equations are focused on determining the temperature rise from excess concentrations of each of the greenhouse gases caused by human activities. There is no module of an economy. The economic side of the model is limited to a few equations that link market and non-market damages to temperature increases and calculate costs of avoiding or diminishing these damages through adaptation and/or emission reductions. In estimating damages arising from climate change, an "enumerative approach" is taken, which means that total damages are a simple aggregation of damages in individual sectors. There is thus no general equilibrium type of accounting for the many possible interactions between sectors. Although it has been assumed that this will lead to a lower estimate of total damages than that from a model that captures interactions, it is difficult to understand the magnitude of the difference. Climate change impacts are assumed to occur if temperature rises at a rate above some tolerable rate of change or level of temperature. These rates and levels vary with regions, and a regional multiplier captures these differences. Adaptation policies in any given year can increase both the tolerable rate of change and the level of temperature rise. The regional impact of climate change is therefore a function of the regional temperature rise and how much this is in excess of the regional tolerable rate of change or level of temperature that also depends on adaptation policies. A weighted index translates the regional temperature rise into monetary damage by multiplying the excess regional temperature rise by a regionally weighted percentage loss of GDP (based on estimates) times the regions' estimated GDP. This is done for all eight regions in the model, for the market and non-market sectors and for every time period. By adding together market and non-market sector damages, the model finds aggregate damages per region per period, and this can then be discounted with regional and time variable discount rates. To get the net present value of global climate change impacts, the model aggregates the net present values of all regional damages.

Adaptation costs depend on the change in the rate and level of tolerable temperature rise that can be brought about by adaptation policy within each region. With appropriate weighting and use of uncertainty parameters, the net present value of costs can be estimated for different regional adaptation strategies. The costs of 
preventing climate change are based on estimates of mitigating emissions below business as usual levels and are also weighted by region and discounted per time period. Only the direct costs of preventing greenhouse gas emissions are included in the model, although secondary benefits (like the concomitant reduction in atmospheric pollution) can be incorporated by reducing the preventative cost parameters. In many of the model's equations, parameters are used to capture uncertainty like that relating to the equilibrium warming from a doubling of $\mathrm{CO}_{2}$ concentration, or the uncertainty about future growth or policy. In PAGE2002, there are about 80 uncertainty parameters depending on the regions and impact sectors used for a given run.

Although little can be obtained from a comparative analysis of models that fall into this "other models" class, Table 12 presents how uncertainty is treated and how technological change is introduced in these seven models.

A key difference between these models and models of other categories lies in the treatment of uncertain parameters. With the exception of the Community Integrated Assessment System (CIAS) model, all other models feature the capacity to approach uncertainty stochastically, by means of Monte Carlo analysis in FUND (Ackerman and Munitz 2012), IGSM2 (Webster et al. 2003, 2012) and IMAGE (Van Vuuren 2007) and probability distributions in ICAM-3 (e.g. Dowlatabadi 1998). PAGE, as already discussed, incorporates probability distributions for treating a large number of uncertain parameters, as well as Latin hypercube sampling, which was preferred over Monte Carlo analysis.

\section{Concluding Remarks}

This book chapter has tried to convey the broad outlines and main distinguishing features of alternative climate-economy model frameworks. The main objective has been to provide a simple overview and organising scheme into what can be a daunting wealth of different climate-economy or integrated assessment models. Rather than attempting to provide brief descriptions of a large sample of climateeconomy models, the paper has tried to portray the main features of a small number of different classes of models, while delving into some key aspects of the models' perspective, structure, coverage and ways of treating uncertainty and technological advancement. Furthermore, no attempt was made to consider or compare results from alternative models; there are many surveys that compare model outcomes and consider how these differences can be explained either by the features of the model or by the specific assumptions embedded in these. Some suggest that the model framework can have substantial implications on the outcomes. Lanz and Rausch (2011) show systematic differences in outcomes from general equilibrium and energy system models. In contrast, one survey by Edenhofer et al. (2006) suggests that the underlying differences in outcomes lie not necessarily in the model type per se but the assumptions commonly made by the researchers working with different model types. The distinction between "model type" and "assumptions" may be 


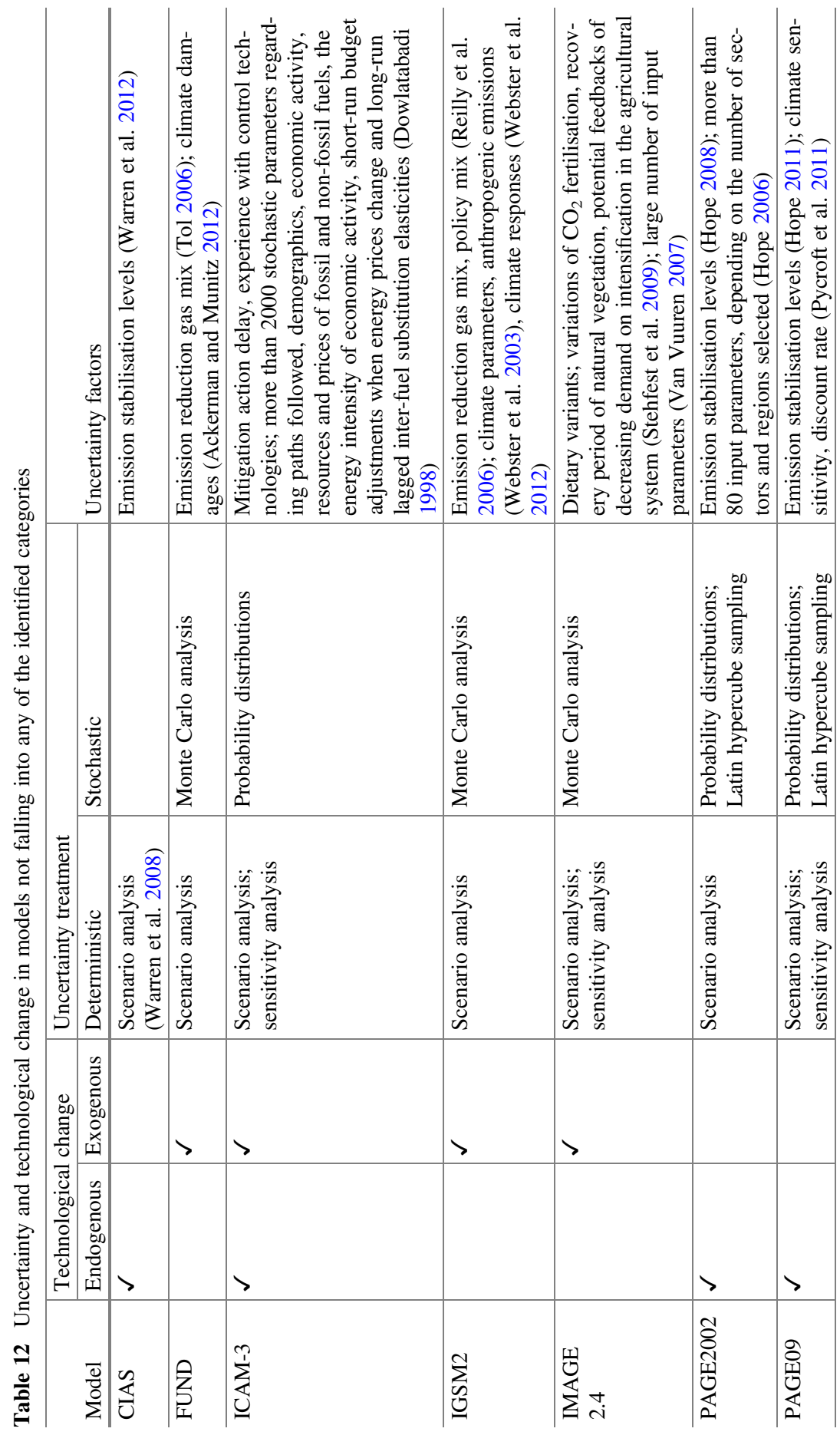


somewhat vague, but certainly a deeper understanding of climate-economy modelling really requires a detailed understanding of the role of the many assumptions explicitly or implicitly incorporated in these. Several climate-economy surveys do focus, inter alia, on just such a comparison of the role of assumptions (e.g. Stanton et al. 2009; Söderholm 2007).

It should be noted that many climate-economy models would not fall easily into any of the broad classifications presented here. Moreover, with the modellers' tendency to continuously develop and improve their models, there is much "crossfertilisation" further blurring distinctions. The diversity of models has many sources. Model selection or design may be driven by different underlying research questions, like whether the focus is on calculating the cost of emission reductions or the longterm damages of climate change or whether one is comparing specific policies or trying to determine an overall optimal global climate policy target. If the focus is on understanding the impacts of climate change to a national economy, a more detailed multisectoral model may be more appropriate than a wealth maximising model that treats the economy as a single sector but captures the long-term global trajectory of the global economy. The differences may reflect deeper philosophical controversies, like whether it is meaningful to assume perfectly functioning markets when the object is to model climate change, which is the grandest instance of market failure extending to so many parts of the economy and with an unprecedented scale in time and space. This is why recent advancements or perspectives call for the use of modelling ensembles that highlight and make use of these differences in structure, design and theoretical foundations, in order to gain better insights (Doukas et al. 2018) and meaningfully inform policy processes; and, even such approaches may miss fundamental aspects that can only be explored with the help of stakeholders (Nikas et al. 2017). These differences may also result from the need to capture one particularly salient feature of climate change like uncertainty. The latter is associated with so many aspects of climate change and respective policy and is therefore, at least to some extent, being treated by means of deterministic or stochastic approaches embedded in the different modelling frameworks.

No doubt these and many other sources of model diversity will continue to drive the development of new and refinement of old models. Although this paper has barely scratched the surface of climate-economy modelling, the following quote seems like an apt closing for the great analytical challenges raised by our need to better understand the required policy response to climate change: "it is difficult to conceive an integrated model that will be able to provide the best answers to all questions. Instead, [...] the relative strengths and weaknesses of the different frameworks ensure that the combined contributions rather than individual models provide really valuable policy insights, to which new approaches and new frameworks for coupling economic and climate models can contribute" (Toth 2005).

Acknowledgements The most important part of this research is based on the H2020 European Commission Project "Transitions pathways and risk analysis for climate change mitigation and adaptation strategies-TRANSrisk" under grant agreement No. 642260. The content of this chapter, the sole responsibility for which lies with the authors, does not necessarily reflect the opinion of the European Commission. 


\section{References}

Ackerman, F., \& Munitz, C. (2012). Climate damages in the FUND model: A disaggregated analysis. Ecological Economics, 77, 219-224.

Ackerman, F., \& Stanton, E. (2012). Climate risks and carbon prices: Revising the social cost of carbon.

Ackerman, F., Stanton, E. A., \& Bueno, R. (2010). Fat tails, exponents, extreme uncertainty: Simulating catastrophe in DICE. Ecological Economics, 69(8), 1657-1665.

Akashi, O., Hijioka, Y., Masui, T., Hanaoka, T., \& Kainuma, M. (2012). GHG emission scenarios in Asia and the world: The key technologies for significant reduction. Energy Economics, 34, S346-S358.

Akimoto, K., Sano, F., Homma, T., Oda, J., Nagashima, M., \& Kii, M. (2010). Estimates of GHG emission reduction potential by country, sector, and cost. Energy Policy, 38(7), 3384-3393.

Akimoto, K., Tomoda, T., Fujii, Y., \& Yamaji, K. (2004). Assessment of global warming mitigation options with integrated assessment model DNE21. Energy Economics, 26(4), 635-653.

Anthoff, D., Hepburn, C., \& Tol, R. S. (2009). Equity weighting and the marginal damage costs of climate change. Ecological Economics, 68(3), 836-849.

Barker, T. (1998). The effects on competitiveness of coordinated versus unilateral fiscal policies reducing GHG emissions in the EU: An assessment of a 10\% reduction by 2010 using the E3ME model. Energy Policy, 26(14), 1083-1098.

Barker, T. (1999). Achieving a $10 \%$ cut in Europe's carbon dioxide emissions using additional excise duties: Coordinated, uncoordinated and unilateral action using the econometric model E3ME. Economic Systems Research, 11(4), 401-422.

Barker, T., \& Ekins, P. (2001). How high are the costs of Kyoto for the US Economy (No. 4). Tyndall Centre working paper.

Barker, T., \& Rosendahl, K. E. (2000). Ancillary benefits of GHG mitigation in Europe: SO2, NOx and PM10 reductions from policies to meet Kyoto targets using the E3ME model and Externe valuations. Ancillary benefits and costs of greenhouse gas mitigation (pp. 413-450).

Barker, T., \& Scrieciu, S. Ş. (2010). Modeling low climate stabilization with E3MG: Towards a 'new economics' approach to simulating energy-environment-economy system dynamics. The Energy Journal, 31, 137-164.

Barker, T., \& Zagame, P. (1995). E3ME: An energy-environment-economy model for Europe. Brüssel: European Commission.

Barker, T., Anger, A., Chewpreecha, U., \& Pollitt, H. (2012). A new economics approach to modelling policies to achieve global 2020 targets for climate stabilisation. International Review of Applied Economics, 26(2), 205-221.

Barker, T., Ekins, P., \& Foxon, T. (2007). The macro-economic rebound effect and the UK economy. Energy Policy, 35(10), 4935-4946.

Barker, T., Pan, H., Köhler, J., Warren, R., \& Winne, S. (2006). Decarbonizing the global economy with induced technological change: Scenarios to 2100 using E3MG. The Energy Journal, 27, 241-258.

Barker, T., Scrieciu, S. S., \& Foxon, T. (2008). Achieving the G8 50\% target: Modelling induced and accelerated technological change using the macro-econometric model E3MG. Climate Policy, 8(Suppl 1), S30-S45.

Barreto, L., \& Kypreos, S. (2004). Endogenizing R\&D and market experience in the "bottom-up" energy-systems ERIS model. Technovation, 24(8), 615-629.

Bchir, H., Decreux, Y., Guérin, J. L., \& Jean, S. (2002). MIRAGE, a computable general equilibrium model for trade policy analysis (Vol. 17). CEPII Working paper.

Bchir, M. H., Fontagné, L., \& Zanghieri, P. (2003). The impact of EU enlargement on Member States: A CGE approach (Vol. 10). CEPII.

Bernstein, P. M., Montgomery, W. D., \& Rutherford, T. F. (1999a). Global impacts of the Kyoto agreement: Results from the MS-MRT model. Resource and Energy Economics, 21(3), 375-413. 
Bernstein, P. M., Montgomery, W. D., Rutherford, T. F., \& Yang, G. F. (1999b). Effects of restrictions on international permit trading: The MS-MRT model. The Energy Journal, 20, 221-256.

Bollen, J. (2015). The value of air pollution co-benefits of climate policies: Analysis with a global sector-trade CGE model called WorldScan. Technological Forecasting and Social Change, 90, $178-191$.

Bollen, J. C., \& Gielen, A. M. (1999). Economic impacts of multilateral emission reduction policies: Simulations with WorldScan. In International environmental agreements on climate change (pp. 155-167). Dordrecht: Springer Netherlands.

Bosello, F. (2010). Adaptation, mitigation and 'green' $R \& D$ to combat global climate change. Insights from an empirical integrated assessment exercise.

Bosello, F., De Cian, E., Eboli, F., \& Parrado, R. (2009). Macro economic assessment of climate change impacts: A regional and sectoral perspective. Impacts of climate change and biodiversity effects. Final report of the CLIBIO project, European Investment Bank, University Research Sponsorship Programme.

Bosello, F., Eboli, F., Parrado, R., \& Rosa, R. (2010). REDD in the carbon market: A general equilibrium analysis.

Bosetti, V., Carraro, C., \& Galeotti, M. (2005). The dynamics of carbon and energy intensity in a model of endogenous technical change.

Bosetti, V., Carraro, C., Duval, R., Sgobbi, A., \& Tavoni, M. (2009). The role of $R \& D$ and technology diffusion in climate change mitigation: New perspectives using the WITCH model.

Bosetti, V., Golub, A., Markandya, A., Massetti, E., \& Tavoni, M. (2008). Abatement cost uncertainty and policy instrument selection. A dynamic analysis. In Modelling environmentimproving technological innovations under uncertainty (pp. 127-157). Oxon: Routledge.

Bosetti, V., Massetti, E., \& Tavoni, M. (2007). The WITCH model: Structure, baseline, solutions.

Bouwman, A. F., Kram, T., \& Klein Goldewijk, K. (2006). Integrated modelling of global environmental change. An overview of IMAGE 2.4.

Buchner, B., \& Carraro, C. (2005). Modelling climate policy: Perspectives on future negotiations. Journal of Policy Modeling, 27(6), 711-732.

Bukowski, M., \& Kowal, P. (2010). Large scale, multi-sector DSGE model as a climate policy assessment tool. Working Paper 3, Instytut Badań Strukturalnych, Warszawa.

Buonanno, P., Carraro, C., \& Galeotti, M. (2003). Endogenous induced technical change and the costs of Kyoto. Resource and Energy Economics, 25(1), 11-34.

Burniaux, J. M. (1998). How important is market power in achieving Kyoto? An assessment based on the GREEN model (pp. 17-18). Proceedings of the Workshop on Economic Modelling and Climate Change.

Burniaux, J. M., \& Truong, T. P. (2002). GTAP-E: An energy-environmental version of the GTAP model. GTAP Technical Papers, 18.

Burniaux, J. M., Martin, J. P., Nicoletti, G., \& Martins, J. O. (1992). GREEN a multi-sector, multiregion general equilibrium model for quantifying the costs of curbing $\mathrm{CO} 2$ emissions.

Cambridge Econometrics. (2014, April). E3ME technical manual, version 6.0. University of Cambridge, Cambridge.

Capros, P., De Vita, A., Tasios, N., Siskos, P., Kannavou, M., Petropoulos, A., Evangelopoulou, S., Zampara, M., Papadopoulos, D., Nakos, C., \& Paroussos, L. (2016). EU Reference Scenario 2016-Energy, transport and GHG emissions Trends to 2050.

Capros, P., Mantzos, L., Kolokotsas, D., Ioannou, N., Georgakopoulos, T., Filippopoulitis, A., \& Antoniou, Y. (1998). The PRIMES energy system model-reference manual. National Technical University of Athens.

Capros, P., Mantzos, L., Papandreou, V., Tasios, N., \& Mantzaras, A. (2007). Energy systems analysis of CCS Technology; PRIMES model scenarios. E3ME-lab/ICCS/National Technical University of Athens, Athens. Final report to DG ENV.

Capros, P., Mantzos, L., Vouyoukas, L., \& Petrellis, D. (1999). European energy and CO2 emissions trends to 2020: PRIMES model v. 2. Bulletin of Science, Technology \& Society, 19 (6), 474-492. 
Capros, P., Tasios, N., De Vita, A., Mantzos, L., \& Paroussos, L. (2012). Model-based analysis of decarbonising the EU economy in the time horizon to 2050. Energy strategy reviews, 1(2), $76-84$

Ciscar, J. C., Soria, A., Goodess, C. M., Christensen, O. B., Iglesias, A., Garrote, L., Moneo, M., Quiroga, S., Feyen, L., Dankers, R., \& Nicholls, R. (2009). Climate change impacts in Europe. Final report of the PESETA research project (No. JRC55391). Directorate Growth \& Innovation and JRC-Seville, Joint Research Centre.

Cooper, A., Livermore, S., Rossi, V., Wilson, A., \& Walker, J. (1999). The economic implications of reducing carbon emissions: A cross-country quantitative investigation using the Oxford Global Macroeconomic and Energy Model. The Energy Journal, 20, 335-365.

Crassous, R., Hourcade, J. C., \& Sassi, O. (2006). Endogenous structural change and climate targets modeling experiments with Imaclim-R. The Energy Journal, 27, 259-276.

Criqui, P., Cattier, F., Kouvaritakis, N., \& Thonet, C. (1998). Technological scenarios, climate change and emission trading: EC-IEA study on energy technology and climate change simulations using the POLES world model. Sevilla: IPTS.

Criqui, P., Mima, S., \& Viguier, L. (1999). Marginal abatement costs of CO2 emission reductions, geographical flexibility and concrete ceilings: An assessment using the POLES model. Energy Policy, 27(10), 585-601.

Dagoumas, A. S., \& Barker, T. S. (2010). Pathways to a low-carbon economy for the UK with the macro-econometric E3MG model. Energy Policy, 38(6), 3067-3077.

Dai, H., Masui, T., Matsuoka, Y., \& Fujimori, S. (2011). Assessment of China's climate commitment and non-fossil energy plan towards 2020 using hybrid AIM/CGE model. Energy Policy, 39(5), 2875-2887.

DeCanio, S. (2003). Economic models of climate change: A critique. Berlin: Springer.

Den Elzen, M. G. J. (2005). Analysis of future commitments and costs of countries for the "SouthNorth Dialogue" proposal using the FAIR 2.1 world model. No. MNP-report, 728001032.

Doukas, H., Nikas, A., González-Eguino, M., Arto, I., \& Anger-Kraavi, A. (2018). From integrated to integrative: Delivering on the Paris Agreement. Sustainability, 10(7).

Dowlatabadi, H. (1995). Integrated assessment models of climate change: An incomplete overview. Energy Policy, 23(4), 289-296.

Dowlatabadi, H. (1998). Sensitivity of climate change mitigation estimates to assumptions about technical change. Energy Economics, 20(5), 473-493.

Dowlatabadi, H. (2000). Bumping against a gas ceiling. Climatic Change, 46(3), 391-407.

Edenhofer, O., Bauer, N., \& Kriegler, E. (2005a). The impact of technological change on climate protection and welfare: Insights from the model MIND. Ecological Economics, 54(2), 277-292.

Edenhofer, O., Lessmann, K., \& Bauer, N. (2005b). Mitigation strategies and costs of climate protection: The effects of ETC in the hybrid model MIND.

Edenhofer, O., Lessmann, K., Kemfert, C., Grubb, M., \& Köhler, J. (2006). Induced technological change: Exploring its implications for the economics of atmospheric stabilization: Synthesis report from the innovation modeling comparison project. The Energy Journal, 27, 57-107.

Edmonds, J., \& Reiley, J. M. (1985). Global energy-assessing the future.

Edmonds, J., Pitcher, H., \& Sands, R. (2004). Second generation model 2004: An overview. Special Issue on Endogenous, 30, 425-448.

Ekins, P., \& Etheridge, B. (2006). The environmental and economic impacts of the UK climate change agreements. Energy Policy, 34(15), 2071-2086.

Elliott, J., Foster, I., Kortum, S., Munson, T., Cervantes, F. P., \& Weisbach, D. (2010). Trade and carbon taxes. The American Economic Review, 100(2), 465-469.

Fawcett, A. A. (2011). International offsets usage in proposed US climate change legislation. In Modeling the economics of greenhouse gas mitigation: Summary of a workshop.

Finon, D. (1976). Un modele energetique pour la France (Vol. 3). Centre national de la recherche scientifique.

Fishbone, L. G., \& Abilock, H. (1981). Markal, a linear-programming model for energy systems analysis: Technical description of the bnl version. International Journal of Energy Research, 5 (4), 353-375. 
Flamos, A. (2016). A sectoral micro-economic approach to scenario selection and development: The case of the Greek power sector. Energies, 9(2), 77.

Fujino, J., Nair, R., Kainuma, M., Masui, T., \& Matsuoka, Y. (2006). Multi-gas mitigation analysis on stabilization scenarios using AIM global model. The Energy Journal, 27, 343-353.

Füssel, H. M. (2009). An updated assessment of the risks from climate change based on research published since the IPCC Fourth Assessment Report. Climatic Change, 97(3), 469-482.

Füssel, H. M. (2010). Modeling impacts and adaptation in global IAMs. Wiley Interdisciplinary Reviews: Climate Change, 1(2), 288-303.

Gabriel, S. A., Kydes, A. S., \& Whitman, P. (2001). The National Energy Modeling System: A large-scale energy-economic equilibrium model. Operations Research, 49(1), 14-25.

Garnaut, R. (2008). The Garnaut climate change review: Final report. Cambridge: Cambridge University Press.

Gerlagh, R. (2006). ITC in a global growth-climate model with CCS: The value of induced technical change for climate stabilization. The Energy Journal, 27, 223-240.

Gerlagh, R. (2007). Measuring the value of induced technological change. Energy Policy, 35(11), 5287-5297.

Gerlagh, R., \& Van der Zwaan, B. (2006). Options and instruments for a deep cut in $\mathrm{CO}_{2}$ emissions: Carbon dioxide capture or renewables, taxes or subsidies? The Energy Journal, 27, 25-48.

Goettle, R. J., \& Fawcett, A. A. (2009). The structural effects of cap and trade climate policy. Energy Economics, 31, S244-S253.

Goettle, R. J., Ho, M. S., Jorgenson, D. W., Slesnick, D. T., Wilcoxen, P. J., \& EP-W, E. C. (2007). IGEM, an inter-temporal general equilibrium model of the US economy with emphasis on growth, energy and the environment. Prepared for the US Environmental Protection Agency (EPA), Office of Atmospheric Programs, Climate Change Division, EPA Contract EP-W-05035.

Golub, A., Hertel, T. W., \& Sohngen, B. (2009). Land use modelling in a recursively dynamic GTAP framework. In Economic analysis of land use in global climate change policy (Vol. 14, p. 235).

Grassini, M. (2009). Rowing along the computable general equilibrium modelling mainstream. Studies on Russian Economic Development, 20(2), 134-146.

Greening, L. A., \& Bataille, C. (2009). Bottom-up models of energy: Across the spectrum.

Hainoun, A., Aldin, M. S., \& Almoustafa, S. (2010). Formulating an optimal long-term energy supply strategy for Syria using MESSAGE model. Energy Policy, 38(4), 1701-1714.

Hedenus, F., Azar, C., \& Lindgren, K. (2006). Induced technological change in a limited foresight optimization model. The Energy Journal, 27, 109-122.

Hickman, R., Ashiru, O., \& Banister, D. (2010). Transport and climate change: Simulating the options for carbon reduction in London. Transport Policy, 17(2), 110-125.

Hitz, S., \& Smith, J. (2004). Estimating global impacts from climate change. Global Environmental Change, 14(3), 201-218.

Hof, A. F. (2010). International mitigation and adaptation strategies for climate change policy: An integrated assessment approach.

Hof, A. F., de Bruin, K. C., Dellink, R. B., den Elzen, M. G., \& van Vuuren, D. P. (2009). The effect of different mitigation strategies on international financing of adaptation. Environmental Science \& Policy, 12(7), 832-843.

Hof, A. F., De Bruin, K., Dellink, R., den Elzen, M. G. J., \& van Vuuren, D. P. (2012). Costs, benefits and inter-linkages between adaptation and mitigation. Global Climate Governance Beyond.

Hof, A. F., den Elzen, M. G., \& van Vuuren, D. P. (2008). Analysing the costs and benefits of climate policy: Value judgements and scientific uncertainties. Global Environmental Change, $18(3), 412-424$.

Hope, C. (2006). The marginal impact of CO2 from PAGE2002: An integrated assessment model incorporating the IPCC's five reasons for concern. Integrated Assessment, 6(1), 19-56.

Hope, C. (2009). How deep should the deep cuts be? Optimal CO2 emissions over time under uncertainty. Climate Policy, 9(1), 3-8.

Hope, C. (2011). The social cost of CO2 from the PAGE09 model. 
Hope, C. (2013). Critical issues for the calculation of the social cost of CO2: Why the estimates from PAGE09 are higher than those from PAGE2002. Climatic Change, 117(3), 531-543.

Hope, C. W. (2008). Optimal carbon emissions and the social cost of carbon over time under uncertainty. Integrated Assessment Journal, 8(1), 107-122.

Hope, C., Anderson, J., \& Wenman, P. (1993). Policy analysis of the greenhouse effect: An application of the PAGE model. Energy Policy, 21(3), 327-338.

Hourcade, J. C., Richels, R., Robinson, J., Chandler, W., Davidson, O., Finon, D., Grubb, M. J., Halsneas, K., Hogan, K., Jaccard, M., \& Krause, F. (1996). Estimating the costs of mitigating greenhouse gases (pp. 263-296). Climate Change 1995, Economic and Social Dimensions of Climate Change, Contribution of Working Group II.

Ianchovichina, E., Darwin, R., \& Shoemaker, R. (2001). Resource use and technological progress in agriculture: A dynamic general equilibrium analysis. Ecological Economics, 38(2), 275-291.

International Energy Agency. (2010). World Energy Outlook 2010. Paris: OECD/International Energy Agency.

Jakeman, G., \& Fisher, B. S. (2006). Benefits of multi-gas mitigation: An application of the Global Trade and Environment Model (GTEM). The Energy Journal, 27, 323-342.

Jebaraj, S., \& Iniyan, S. (2006). A review of energy models. Renewable and Sustainable Energy Reviews, 10(4), 281-311.

Jorgenson, D. W., Goettle, R. J., Hurd, B. H., Smith, J. B., Chestnut, L. G., \& Mills, D. M. (2004). US market consequences of global climate change. Washington, DC: Pew Center on Global Climate Change.

Junankar, S., Lofsnaes, O., \& Summerton, P. (2007). MDM-E3. A short technical description. Cambridge: Cambridge Econometrics.

Kainuma, M., Matsuoka, Y., \& Morita, T. (1999). Analysis of post-Kyoto scenarios: The AsianPacific integrated model. The Energy Journal, 27, 207-220.

Kainuma, M., Matsuoka, Y., \& Morita, T. (2000). The AIM/end-use model and its application to forecast Japanese carbon dioxide emissions. European Journal of Operational Research, 122 (2), 416-425.

Kainuma, M., Matsuoka, Y., \& Morita, T. (Eds.). (2011). Climate policy assessment: Asia-Pacific integrated modeling. Tokyo: Springer Science \& Business Media.

Kainuma, M., Matsuoka, Y., Hibino, G., Shimada, K., Ishii, H., Matsui, S., \& Morita, T. (2003). Application of AIM/Enduse model to Japan. In Climate policy assessment (pp. 155-176). Tokyo: Springer Japan.

Karkatsoulis, P., Siskos, P., Paroussos, L., \& Capros, P. (2017). Simulating deep CO2 emission reduction in transport in a general equilibrium framework: The GEM-E3T model. Transportation Research Part D: Transport and Environment, 55, 343-358.

Kelly, D. L., \& Kolstad, C. D. (1999). Integrated assessment models for climate change control. International Yearbook of Environmental and Resource Economics, 2000, 171-197.

Kemfert, C. (2001). Economy-energy-climate interaction: The model wiagem.

Kemfert, C. (2005). Induced technological change in a multi-regional, multi-sectoral, integrated assessment model (WIAGEM): Impact assessment of climate policy strategies. Ecological Economics, 54(2), 293-305.

Kemfert, C., \& Truong, T. (2007). Impact assessment of emissions stabilization scenarios with and without induced technological change. Energy Policy, 35(11), 5337-5345.

Kemfert, C., Truong, T. P., \& Bruckner, T. (2006). Economic impact assessment of climate change-A multi-gas investigation with WIAGEM-GTAPEL-ICM. The Energy Journal, 27, 441-460.

Keppo, I., \& van der Zwaan, B. (2012). The impact of uncertainty in climate targets and CO2 storage availability on long-term emissions abatement. Environmental Modeling \& Assessment, 17(1-2), 177-191.

Kesicki, F., \& Yanagisawa, A. (2015). Modelling the potential for industrial energy efficiency in IEA's World Energy Outlook. Energy Efficiency, 8(1), 155-169.

Kitous, A., Criqui, P., Bellevrat, E., \& Chateau, B. (2010). Transformation patterns of the worldwide energy system-scenarios for the century with the POLES model. The Energy Journal, 27, $49-82$. 
Koji, T., Takanobu, K., Atsushi, K., Norihiro, I., \& Masaji, S. (2009). Measuring weak sustainability for the future: Calculating genuine saving with population change by an integrated assessment model.

Kopp, R. E., \& Mignone, B. K. (2012). The US Government's social cost of carbon estimates after their first two years: Pathways for improvement.

Kouvaritakis, N., Soria, A., \& Isoard, S. (2000a). Modelling energy technology dynamics: Methodology for adaptive expectations models with learning by doing and learning by searching. International Journal of Global Energy Issues, 14(1-4), 104-115.

Kouvaritakis, N., Soria, A., Isoard, S., \& Thonet, C. (2000b). Endogenous learning in world postKyoto scenarios: Application of the POLES model under adaptive expectations. International Journal of Global Energy Issues, 14(1-4), 222-248.

Kratena, K., \& Streicher, G. (2009). Macroeconomic input-output modelling: Structures, functional forms and closure rules. International Input-Output Association Working Paper WPIOX, 09-009.

Kremers, H., Nijkamp, P., \& Wang, S. (2000). Mailing issues on climate change policiesA discussion of the GTAP-E Model (No. 00-099/3). Tinbergen Institute Discussion Paper.

Kurosawa, A. (2004). Carbon concentration target and technological choice. Energy Economics, 26 (4), 675-684.

Kurosawa, A. (2006). Multigas mitigation: An economic analysis using GRAPE model. The Energy Journal, 27, 275-288.

Kurosawa, A., Yagita, H., Zhou, W., Tokimatsu, K., \& Yanagisawa, Y. (1999). Analysis of carbon emission stabilization targets and adaptation by integrated assessment model. The Energy Journal, 27, 157-175.

Kypreos, S. (2007). A MERGE model with endogenous technological change and the cost of carbon stabilization. Energy Policy, 35(11), 5327-5336.

Kypreos, S. (2008). Stabilizing global temperature change below thresholds: Monte Carlo analyses with MERGE. Computational Management Science, 5(1), 141-170.

Kypreos, S., Barreto, L., Capros, P., \& Messner, S. (2000). ERIS: A model prototype with endogenous technological change. International Journal of Global Energy Issues, 14(1-4), 347-397.

Laborde, D., Martin, W., \& Van der Mensbrugghe, D. (2016). Measuring the impacts of global trade reform with optimal aggregators of distortions. Review of International Economics, 25, 403-425.

Lanz, B., \& Rausch, S. (2011). General equilibrium, electricity generation technologies and the cost of carbon abatement: A structural sensitivity analysis. Energy Economics, 33(5), 1035-1047.

Lapillonne, B. (1978). MEDEE 2: A model for long-term energy demand evaluation.

Lapillonne, B. (1980). Long term perspectives of the US energy demand: Application of the MEDEE 2 model to the US. Energy, 5(3), 231-257.

Lecocq, F., \& Shalizi, Z. (2007). How might climate change affect economic growth in developing countries? A review of the growth literature with a climate lens. Policy Research Working Papers, 4315.

Lejour, A., Veenendaal, P., Verweij, G., \& van Leeuwen, N. (2006). WorldScan; a model for international economic policy analysis (No. 111). CPB Netherlands Bureau for Economic Policy Analysis.

Link, P. M., \& Tol, R. S. (2004). Possible economic impacts of a shutdown of the thermohaline circulation: An application of FUND. Portuguese Economic Journal, 3(2), 99-114.

Manne, A. S., \& Richels, R. G. (2005). MERGE: An integrated assessment model for global climate change. In Energy and environment (pp. 175-189). Springer US.

Manne, A., Mendelsohn, R., \& Richels, R. (1995). MERGE: A model for evaluating regional and global effects of GHG reduction policies. Energy Policy, 23(1), 17-34.

Masui, T. (2005). Policy evaluations under environmental constraints using a computable general equilibrium model. European Journal of Operational Research, 166(3), 843-855.

Masui, T., Hanaoka, T., Hikita, S., \& Kainuma, M. (2006a). Assessment of $\mathrm{CO}_{3}$ reductions and economic impacts considering energy-saving investments. The Energy Journal, 27, 175-190. 
Masui, T., Matsuoka, Y., \& Kainuma, M. (2006b). Long-term CO2 emission reduction scenarios in Japan. Environmental Economics and Policy Studies, 7(3), 347-366.

Masui, T., Rana, A., \& Matsuoka, Y. (2003). AIM/material model. In Climate policy assessment (pp. 177-196). Springer Japan.

Matsuoka, Y., Kainuma, M., \& Morita, T. (1995). Scenario analysis of global warming using the Asian Pacific Integrated Model (AIM). Energy Policy, 23(4-5), 357-371.

Mattsson, N. (2002). Introducing uncertain learning in an energy system model: A pilot study using GENIE. International Journal of Global Energy Issues, 18(2-4), 253-265.

Mattsson, N., \& Wene, C. O. (1997). Assessing new energy technologies using an energy system model with endogenized experience curves. International Journal of Energy Research, 21(4), 385-393.

McKibbin, W. J., \& Wilcoxen, P. J. (1999). The theoretical and empirical structure of the G-Cubed model. Economic Modelling, 16(1), 123-148.

McKibbin, W. J., \& Wilcoxen, P. J. (2009). Uncertainty and climate change policy design. Journal of Policy Modeling, 31(3), 463-477.

McKibbin, W. J., Lee, J. W., \& Cheong, I. (2004). A dynamic analysis of the Korea-Japan free trade area: Simulations with the G-cubed Asia-Pacific model. International Economic Journal, 18(1), 3-32.

Mendelsohn, R., \& Williams, L. (2004). Comparing forecasts of the global impacts of climate change. Mitigation and Adaptation Strategies for Global Change, 9(4), 315-333.

Mendelsohn, R., Morrison, W., Schlesinger, M. E., \& Andronova, N. G. (2000). Country-specific market impacts of climate change. Climatic Change, 45(3-4), 553-569.

Mendelsohn, R., Nordhaus, W., \& Shaw, D. (1999). The impact of climate variation on US agriculture (pp. 55-74). Cambridge: Cambridge University Press.

Mercure, J. F., Pollitt, H., Edwards, N. R., Holden, P. B., Chewpreecha, U., Salas, P., Lam, A., Knobloch, F., \& Vinuales, J. (2017). Environmental impact assessment for climate change policy with the simulation-based integrated assessment model E3ME-FTT-GENIE. Energy Strategy Reviews, 20, 195-208.

Messner, S. (1997). Endogenized technological learning in an energy systems model. Journal of Evolutionary Economics, 7(3), 291-313.

Mima, S., \& Criqui, P. (2009). Assessment of the impacts under future climate change on the energy systems with the POLES model. In International energy workshop.

Mundaca, L., Neij, L., Worrell, E., \& McNeil, M. (2010). Evaluating energy efficiency policies with energy-economy models. Annual Review of Environment and Resources, 35, 305-344.

Narita, D., Tol, R. S., \& Anthoff, D. (2009). Damage costs of climate change through intensification of tropical cyclone activities: An application of FUND. Climate Research, 39(2), 87-97.

Nicoletti, G., \& Oliveira-Martins, J. (1993). Global effects of the European carbon tax. In The European carbon tax: An economic assessment (pp. 15-48). Springer Netherlands.

Nijkamp, P., Wang, S., \& Kremers, H. (2005). Modeling the impacts of international climate change policies in a CGE context: The use of the GTAP-E model. Economic Modelling, 22(6), 955-974.

Nikas, A., Doukas, H., Lieu, J., Alvarez Tinoco, R., Charisopoulos, V., \& van der Gaast, W. (2017). Managing stakeholder knowledge for the evaluation of innovation systems in the face of climate change. Journal of Knowledge Management, 21(5), 1013-1034.

Nilsson, C. (1999). A unilateral versus a multilateral carbon dioxide tax - A numerical analysis with the European Model GEM-E3 (No. 66).

Nordhaus, W. (2007). Accompanying notes and documentation on development of DICE-2007 model: Notes on DICE-2007. delta. v8 as of September 21, 2007. Miscellaneous publication, Yale University, New Haven, NE.

Nordhaus, W. D. (1994). Managing the global commons: The economics of climate change (Vol. 31). Cambridge, MA: MIT Press.

Nordhaus, W. D. (2002). Modeling induced innovation in climate-change policy. Technological Change and the Environment, 9, 259-290.

Nordhaus, W. D. (2008). A question of balance: Weighing the options on global warming policies. New Haven, CT: Yale University Press. 
Nordhaus, W. D. (2010). Economic aspects of global warming in a post-Copenhagen environment. Proceedings of the National Academy of Sciences, 107(26), 11721-11726.

Nordhaus, W. D. (2014). A question of balance: Weighing the options on global warming policies. New Haven, CT: Yale University Press.

Nordhaus, W. D., \& Boyer, J. (2000). Warming the world: Economic models of global warming. Cambridge, MA: MIT Press.

Nordhaus, W. D., \& Yang, Z. (1996). A regional dynamic general-equilibrium model of alternative climate-change strategies. The American Economic Review, 86, 741-765.

Oda, J., Akimoto, K., Sano, F., \& Homma, T. (2009). Diffusion of CCS and energy efficient technologies in power and iron \& steel sectors. Energy Procedia, 1(1), 155-161.

Ortiz, R. A., \& Markandya, A. (2009). Integrated impact assessment models of climate change with an emphasis on damage functions: A literature review. Bilbao, Spain.

Paltsev, S., Reilly, J. M., Jacoby, H. D., Eckaus, R. S., McFarland, J. R., Sarofim, M. C., Asadoorian, M. O., \& Babiker, M. H. (2005). The MIT emissions prediction and policy analysis (EPPA) model: Version 4. MIT Joint Program on the Science and Policy of Global Change.

Pant, H. M. (2007). GTEM draft: Global trade and environmental model. Australian Bureau of Agricultural and Resource Economics.

Pant, H., Tulpulé, V., \& Fisher, B. S. (2007). Global trade and environment model. Department of Agriculture: Australian Bureau of Agricultural and Resource Economics and Sciences, Canberra, Australia.

Papadelis, S., Flamos, A., \& Psarras, J. (2013). A framework to address uncertainties in energy policy formulation. Energy Sources, Part B: Economics, Planning, and Policy, 8(3), 270-278.

Parrado, R., \& De Cian, E. (2014). Technology spillovers embodied in international trade: Intertemporal, regional and sectoral effects in a global CGE framework. Energy Economics, $41,76-89$.

Parson, E. A., \& Fisher-Vanden, A. K. (1997). Integrated assessment models of global climate change. Annual Review of Energy and the Environment, 22(1), 589-628.

Peck, S. C., \& Teisberg, T. J. (1993). Global warming uncertainties and the value of information: An analysis using CETA. Resource and Energy Economics, 15(1), 71-97.

Peck, S. C., \& Teisberg, T. J. (1995). International CO2 emissions control: An analysis using CETA. Energy Policy, 23(4-5), 297-308.

Peck, S. C., \& Teisberg, T. J. (1999). $\mathrm{CO}_{2}$ emissions control agreements: Incentives for regional participation. The Energy Journal, 27, 367-390.

Pfenninger, S. (2015). Calliope: A multi-scale energy systems (MUSES) modeling framework. Release v0, 3.

Plambeck, E. L., Hope, C., \& Anderson, J. (1997). The Page95 model: Integrating the science and economics of global warming. Energy Economics, 19(1), 77-101.

Plinke, E., Haasis, H. D., Rentz, O., \& Sivrioglu, M. (1990). Analysis of energy and environmental problems in Turkey by using a decision support model. Ambio, 19, 75-81.

Popp, D. (2004). ENTICE: Endogenous technological change in the DICE model of global warming. Journal of Environmental Economics and Management, 48(1), 742-768.

Popp, D. (2006a). Comparison of climate policies in the ENTICE-BR model. The Energy Journal, 27, 163-174.

Popp, D. (2006b). ENTICE-BR: The effects of backstop technology R\&D on climate policy models. Energy Economics, 28(2), 188-222.

Pycroft, J., Vergano, L., Hope, C., Paci, D., \& Ciscar, J. C. (2011). A tale of tails: Uncertainty and the social cost of carbon dioxide.

Rafaj, P., \& Kypreos, S. (2007). Internalisation of external cost in the power generation sector: Analysis with Global Multi-regional MARKAL model. Energy Policy, 35(2), 828-843.

Rana, A., \& Morita, T. (2000). Scenarios for greenhouse gas emission mitigation: A review of modeling of strategies and policies in integrated assessment models. Environmental Economics and Policy Studies, 3(2), 267-289.

Redondo, P. D., \& van Vliet, O. (2015). Modelling the energy future of Switzerland after the phase out of nuclear power plants. Energy Procedia, 76, 49-58. 
Reilly, J., Sarofim, M., Paltsev, S., \& Prinn, R. (2006). The role of non- $\mathrm{CO}_{3}$ GHGs in climate policy: Analysis using the MIT IGSM. The Energy Journal, 27, 503-520.

Robinson, S. (2006). Macro models and multipliers: Leontief, Stone, Keynes, and CGE models. In Poverty, inequality and development (pp. 205-232).

Rosendahl, K. E. (2004). Cost-effective environmental policy: Implications of induced technological change. Journal of Environmental Economics and Management, 48(3), 1099-1121.

Rout, U. K., Akimoto, K., Sano, F., Oda, J., Homma, T., \& Tomoda, T. (2008). Impact assessment of the increase in fossil fuel prices on the global energy system, with and without $\mathrm{CO} 2$ concentration stabilization. Energy Policy, 36(9), 3477-3484.

Sano, F., Akimoto, K., Homma, T., \& Tomoda, T. (2005). Analysis of technological portfolios for CO2 stabilizations and effects of technological changes.

Ščasný, M., Píša, V., Pollitt, H., \& Chewpreecha, U. (2009). Analyzing macroeconomic effects of environmental taxation in the Czech Republic with the econometric E3ME model. Finance a Uver: Czech Journal of Economics \& Finance, 59(5), 460-491.

Schultz, P. A., \& Kasting, J. F. (1997). Optimal reductions in CO2 emissions. Energy Policy, 25(5), 491-500.

Schumacher, K., \& Sands, R. D. (2006). Innovative energy technologies and climate policy in Germany. Energy Policy, 34(18), 3929-3941.

Schwanitz, V. J. (2013). Evaluating integrated assessment models of global climate change. Environmental Modelling \& Software, 50, 120-131.

Schellnhuber, H. J., Warren, R., Haxeltine, A., \& Naylor, L. (2003). Developments in integrated assessment: The co-productive approach. In Proceedings of OECD Workshop on the Benefits of Climate Policy.

Scott, M. J., Sands, R. D., Edmonds, J., Liebetrau, A. M., \& Engel, D. W. (1999). Uncertainty in integrated assessment models: Modeling with MiniCAM 1.0. Energy Policy, 27(14), 855-879.

Seebregts, A. J., Goldstein, G. A., \& Smekens, K. (2002). Energy/environmental modeling with the MARKAL family of models. In Operations research proceedings 2001 (pp. 75-82). Berlin: Springer.

Seebregts, A., Kram, T., Schaeffer, G. J., \& Bos, A. (2000). Endogenous learning and technology clustering: Analysis with MARKAL model of the Western European energy system. International Journal of Global Energy Issues, 14(1-4), 289-319.

Siskos, P., Capros, P., \& De Vita, A. (2015). CO2 and energy efficiency car standards in the EU in the context of a decarbonisation strategy: A model-based policy assessment. Energy Policy, 84, 22-34.

Söderholm, P. (2007). Modelling the economic costs of climate policy. Luleå University of Technology.

Sokolov, A. P., Schlosser, C. A., Dutkiewicz, S., Paltsev, S., Kicklighter, D. W., Jacoby, H. D., Prinn, R. G., Forest, C. E., Reilly, J. M., Wang, C., \& Felzer, B. S. (2005). MIT integrated global system model (IGSM) version 2: Model description and baseline evaluation. MIT Joint Program on the Science and Policy of Global Change.

Sorrell, S. (2009). Jevons' Paradox revisited: The evidence for backfire from improved energy efficiency. Energy policy, 37(4), 1456-1469.

Stanton, E. A., Ackerman, F., \& Kartha, S. (2009). Inside the integrated assessment models: Four issues in climate economics. Climate and Development, 1(2), 166-184.

Stehfest, E., Bouwman, L., Van Vuuren, D. P., Den Elzen, M. G., Eickhout, B., \& Kabat, P. (2009). Climate benefits of changing diet. Climatic Change, 95(1-2), 83-102.

Sullivan, P., Krey, V., \& Riahi, K. (2013). Impacts of considering electric sector variability and reliability in the MESSAGE model. Energy Strategy Reviews, 1(3), 157-163.

Tol, R. S. (1997). On the optimal control of carbon dioxide emissions: An application of FUND. Environmental Modeling and Assessment, 2(3), 151-163.

Tol, R. S. (2002). Welfare specifications and optimal control of climate change: An application of fund. Energy Economics, 24(4), 367-376.

Tol, R. S. (2006). Multi-gas emission reduction for climate change policy: An application of FUND. The Energy Journal, 27, 235-250. 
Tol, R. S. (2010). Carbon dioxide mitigation. In B. Lomborg (Ed.), Smart solutions to climate change: Comparing costs and benefits (pp. 74-105). New York: Cambridge University Press.

Tol, R. S., \& Fankhauser, S. (1998). On the representation of impact in integrated assessment models of climate change. Environmental Modeling and Assessment, 3(1), 63-74.

Toth, F. L. (2005). Coupling climate and economic dynamics: Recent achievements and unresolved problems. In The coupling of climate and economic dynamics (pp. 35-68). Springer Netherlands.

Tulpulé, V., Brown, S., Lim, J., Polidano, C., Pant, H., \& Fisher, B. S. (1998). An economic assessment of the Kyoto Protocol using the Global Trade and Environment Model (pp. 17-18). Proceedings of the Workshop on Economic Modelling and Climate Change.

Turton, H., \& Barreto, L. (2004a). Cars, hydrogen and climate change: A long-term analysis with the ERIS model. 6th IAEE European Conference.

Turton, H., \& Barreto, L. (2004b). The extended energy-systems ERIS model: An overview.

Tyers, R., \& Shi, Q. (2012). Global demographic change, labour force growth and economic performance (Chapter 13, pp. 342-375).

Urban, F. R. M. J., Benders, R. M. J., \& Moll, H. C. (2007). Modelling energy systems for developing countries. Energy Policy, 35(6), 3473-3482.

Van der Mensbrugghe, D. (2005). Linkage technical reference document. Development Prospects Group, The World Bank.

Van der Voort, E. (1982). The EFOM 12C energy supply model within the EC modelling system. Omega, 10(5), 507-523.

van der Zwaan, B., Keppo, I., \& Johnsson, F. (2013). How to decarbonize the transport sector? Energy Policy, 61, 562-573.

Van Regemorter, D. (2005). GEM-E3. Computable General equilibrium model for studying economy-energy-environment interactions for Europe and the world.

Van Vuuren, D. P. (2007). Energy systems and climate policy-long-term scenarios for an uncertain future. Doctoral dissertation, Utrecht University.

Viguier, L. L., Babiker, M. H., \& Reilly, J. M. (2003). The costs of the Kyoto Protocol in the European Union. Energy Policy, 31(5), 459-481.

Von Below, D., \& Persson, T. (2008). Uncertainty, climate change and the global economy (No. w14426). National Bureau of Economic Research.

Wada, K., Sano, F., Akimoto, K., \& Homma, T. (2012). Assessment of Copenhagen pledges with long-term implications. Energy Economics, 34, S481-S486.

Waisman, H., Guivarch, C., Grazi, F., \& Hourcade, J. C. (2012). The IMACLIM-R model: Infrastructures, technical inertia and the costs of low carbon futures under imperfect foresight. Climatic Change, 114(1), 101-120.

Walmsley, T. L., Dimaranan, B. V., \& McDougall, R. A. (2006a). A baseline scenario for the dynamic GTAP model. In Dynamic modeling and applications for global economic analysis (p. 136).

Walmsley, T. L., Hertel, T. W., \& Ianchovichina, E. (2006b). Assessing the impact of China's WTO accession on investment. Pacific Economic Review, 11(3), 315-339.

Warren, R., De La Nava Santos, S., Arnell, N. W., Bane, M., Barker, T., Barton, C., Ford, R., Füssel, H. M., Hankin, R. K., Klein, R., \& Linstead, C. (2008). Development and illustrative outputs of the Community Integrated Assessment System (CIAS), a multi-institutional modular integrated assessment approach for modelling climate change. Environmental Modelling \& Software, 23(5), 592-610.

Warren, R., Yu, R. M. S., Osborn, T. J., \& de la Nava Santos, S. (2012). European drought regimes under mitigated and unmitigated climate change: Application of the Community Integrated Assessment System (CIAS). Climate Research, 51(2), 105-123.

Webster, M. D., Babiker, M., Mayer, M., Reilly, J. M., Harnisch, J., Hyman, R., Sarofim, M. C., \& Wang, C. (2002). Uncertainty in emissions projections for climate models. Atmospheric Environment, 36(22), 3659-3670.

Webster, M., Forest, C., Reilly, J., Babiker, M., Kicklighter, D., Mayer, M., Prinn, R., Sarofim, M., Sokolov, A., Stone, P., \& Wang, C. (2003). Uncertainty analysis of climate change and policy response. Climatic Change, 61(3), 295-320. 
Webster, M., Sokolov, A. P., Reilly, J. M., Forest, C. E., Paltsev, S., Schlosser, A., Wang, C., Kicklighter, D., Sarofim, M., Melillo, J., \& Prinn, R. G. (2012). Analysis of climate policy targets under uncertainty. Climatic Change, 112(3-4), 569-583.

Wei, Y. M., Mi, Z. F., \& Huang, Z. (2015). Climate policy modeling: An online SCI-E and SSCI based literature review. Omega, 57, 70-84.

Wen, Z., Meng, F., \& Chen, M. (2014). Estimates of the potential for energy conservation and CO2 emissions mitigation based on Asian-Pacific Integrated Model (AIM): The case of the iron and steel industry in China. Journal of Cleaner Production, 65, 120-130.

West, G. R. (2002). Modeling structural linkages in dynamic and spatial interindustry systems. In Trade, networks and hierarchies (pp. 225-250). Berlin: Springer.

Weyant, J. P. (1999). The cost of the Kyoto Protocol: A multi-model evaluation. The Energy Journal.

Weyant, J. P. (2009). A perspective on integrated assessment. Climatic Change, 95(3), 317-323.

Wing, I. S. (2011). Computable general equilibrium models for the analysis of economyenvironment interactions. In Research tools in natural resource and environmental economics (p. 255).

Worrell, E., Ramesohl, S., \& Boyd, G. (2004). Advances in energy forecasting models based on engineering economics. Annual Review of Environment and Resources, 29, 345-381.

Xu, Y., \& Masui, T. (2009). Local air pollutant emission reduction and ancillary carbon benefits of SO2 control policies: Application of AIM/CGE model to China. European Journal of Operational Research, 198(1), 315-325.

Yamaji, K., Fujino, J., \& Osada, K. (2000). Global energy system to maintain atmospheric CO2 concentration at $550 \mathrm{ppm}$. Environmental Economics and Policy Studies, 3(2), 159-171.

Yohe, G. W. (1999). The tolerable windows approach: Lessons and limitations. Climatic Change, 41(3), 283-295.

$\mathrm{Yu}, \mathrm{X}$. (2008). Impacts assessment of PHEV charge profiles on generation expansion using national energy modeling system. In Power and energy society general meeting-conversion and delivery of electrical energy in the 21 st century (pp. 1-5). IEEE.

Zaki, C. (2011). Assessing the global effect of trade facilitation: Evidence from the MIRAGE model. Economic Research Forum Working Paper Series (No. 659).

Zhai, F., \& Zhuang, J. (2012). Agricultural impact of climate change: A general equilibrium analysis with special reference to Southeast Asia. In Climate change in Asia and the Pacific: How can countries adapt (pp. 17-35).

Open Access This chapter is licensed under the terms of the Creative Commons Attribution 4.0 International License (http://creativecommons.org/licenses/by/4.0/), which permits use, sharing, adaptation, distribution and reproduction in any medium or format, as long as you give appropriate credit to the original author(s) and the source, provide a link to the Creative Commons license and indicate if changes were made.

The images or other third party material in this chapter are included in the chapter's Creative Commons license, unless indicated otherwise in a credit line to the material. If material is not included in the chapter's Creative Commons license and your intended use is not permitted by statutory regulation or exceeds the permitted use, you will need to obtain permission directly from the copyright holder.

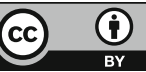

